Article

\title{
Coordinated Development Analysis of the "Resources-Environment-Ecology-Economy-Society" Complex System in China
}

\author{
Mingxia Xie ${ }^{1,2, *}$, Jiayao Wang ${ }^{2,3}$ and Ke Chen ${ }^{2,3}$ \\ 1 School of Resource and Environmental Sciences, Wuhan University, 129 Luoyu Road, Wuhan 430079, China \\ 2 Digital City Engineering Research Center, 1355 Jinji Lake Avenue, Suzhou 215021, China; \\ wrongpu@163.com (J.W.); ck1702@163.com (K.C.) \\ 3 Zhengzhou Institute of Surveying and Mapping, 66 Longhai Road, Zhengzhou 450052, China \\ * Correspondence: xmx0424@whu.edu.cn
}

Academic Editor: Giuseppe Ioppolo

Received: 26 May 2016; Accepted: 17 June 2016; Published: 21 June 2016

\begin{abstract}
The aim of investigating the coordination of the complex system constituted by resources, environment, ecology, economy and society subsystems (CSR3ES), is to achieve sustainable development by: (1) describing the complicated relationships of the inner-subsystems and inter-systems; (2) designing the calculation method of the coordination degree for CSR3ES; (3) analyzing its developing trends from a macro point of view through comprehensive coordination degree; and (4) to determine the direction of system restoration from a micro point of view based on the inner-subsystem and inter-subsystem coordination degree, and to develop specific improvement strategies. By setting a province-level administrative region as a decision-making unit (DMU), the nationwide coordination of CSR3ES was studied. The main conclusions are: (1) The coordination degree between the subsystems is directly influenced by interactions between the elements. (2) Within the provinces and autonomous regions (PARs) in China, the levels of coordinated development of inter-subsystems are high, while the coordinated development between the elements within a single subsystem level are low. Furthermore, a positive coherent effect is exerted on the comprehensive coordination degree of CSR3ES by the inter-system synergistic effects. (3) In terms of spatial correlation, five comprehensive coordinated development modes of CSR3ES are formed: the northeast regional coordination mode group; the northwest regional uncoordinated mode group; the southeast regional coordination mode group; the central regional random mode group; and the Beijing-Tianjin-Hebei polarization mode.
\end{abstract}

Keywords: complex system; sustainable development; index system; coordination degree; coordination management

\section{Introduction}

Currently, many complicated issues face the world's population. These issues include resource problems (over-exploitation of resources, waste of resources, etc.), environmental issues (air pollution, water contamination, etc.), ecological problems (loss of biodiversity, ecology damage, etc.), economic issues (imbalance of economic development, etc.) and social issues (uneven distribution of social resources, etc.). All of these issues are caused, to a large extent, by serious incoordination of the complex system constituted by resources, environment, ecology, economy, and society subsystems (CSR3ES). When the connection and coordination of one or more subsystems occurs, subsystem independence prevails, which leads to the abnormal operation of the entire complex system [1]. The complicated issues that affect national development can only be successfully solved through the cross-synthesis of 
subjects. This will therefore enable the traditional disciplinary boundaries to be broken; it will improve the awareness and understanding of CSR3ES; it will regulate the internal relationships between the subsystems; it will achieve coordinated inter-subsystem operations; and it will restore the entire system into a highly ordered state where "unity" occupies a dominant position.

Sustainable development is an ideological innovation, as well as being a rational development mode proposed after rethinking the uncoordinated development phenomena of the resources, environment, ecology, economy and society (REEES) [2,3]. The coordinated development of a complex system is a process through which the system, or the elements of the system, evolves from simplicity to complexity, from a low to a high level, and from disorder to order on the basis of the coordination, collaboration and virtuous cycle [4]. In order to attain the target of sustainable development, the coordinated development of REEES has to be initially achieved. Coordinated development is a precondition and necessary guarantee of sustainable development, and only a coordinated development can be a sustainable development $[5,6]$. Therefore, coordination is essential for sustainable development, any actions that are detrimental to achieving coordinated development should be adjusted and controlled in order to reasonably exploit and sustainably utilize natural resources; to effectively improve and protect the environment; and to achieve a balanced ecosystem, a healthy and orderly economic development, and a society with harmony, stability, fairness and justice (Figure 1). The coordinated development of REEES has become the optimal model for attaining sustainable development in the future.

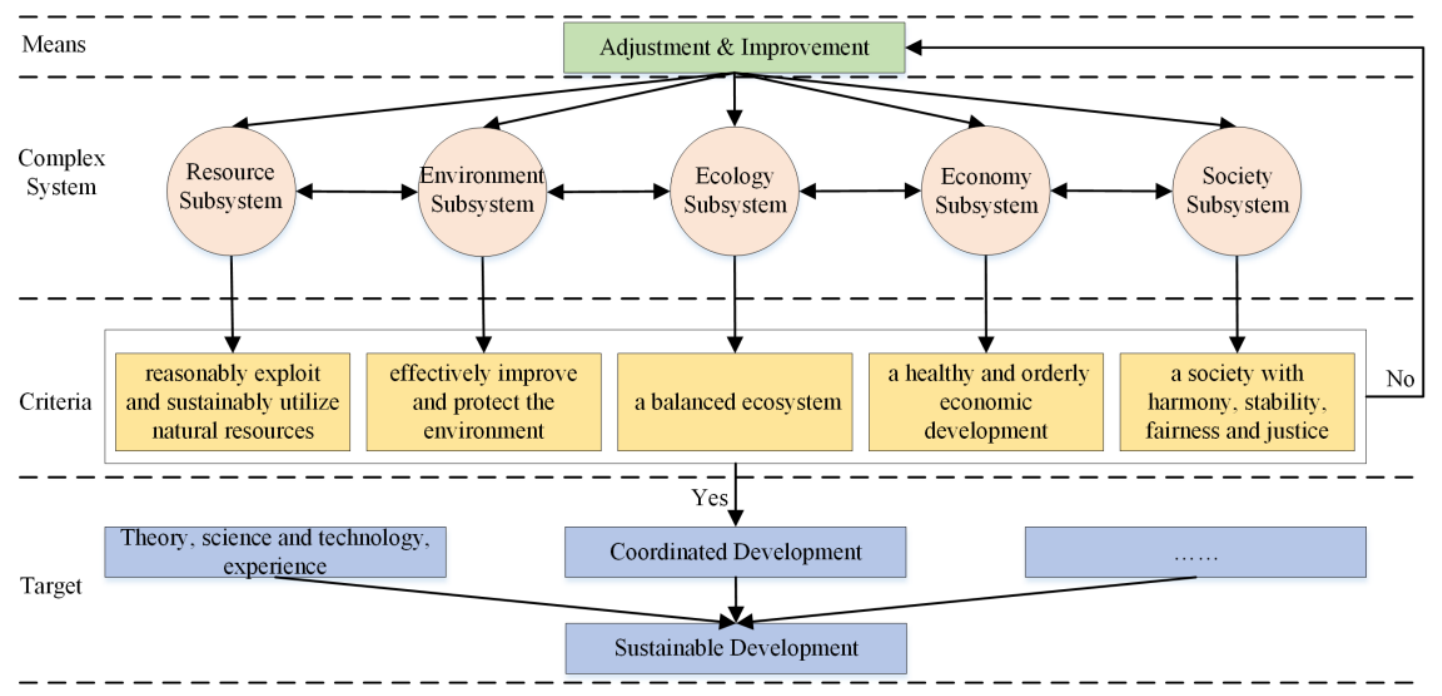

Figure 1. The relationship between coordinated development and sustainable development.

The coordination of a complex system is an important characteristic that reflects the relationships between the various subsystems, and among the internal indexes of these subsystems. The coordination degree of a complex system is a quantitative index that measures the harmony and consistency of the system, or among the elements of the system, during its development. A higher coordination degree indicates a higher consistency of development of the system, or among its elements. On the contrary, a lower coordination degree demonstrates the uncoordinated development of the system, or among its elements, and it identifies the necessity to adopt appropriate measures and strategies to improve and regulate the internal relationships between the subsystems. Coordination has transitioned from initial theoretical discussion to being applied in current research on sustainable development, accompanied by the successive establishment of large index systems and evaluation methods and models. The coordination degree evaluation model can be currently divided into three categories: distance type, change type and integrated type (Table 1). Although some achievements [7-20] have been made in studying the coordination degree of the complex systems, a few issues still need to 
be clarified: Firstly, many terms have emerged, for example resource environment, environmental resources, ecological environment and social economy. Although these terms have been widely debated, no consensus has yet been reached with regard to their definitions. Moreover, there are no corresponding terms in any international environment, ecology, economic or sociology dictionaries [21]. Secondly, current investigations [7-20] largely focus on the coordination of binary or ternary component complex systems, and they rarely focus on the comprehensive analysis and research of REEES, which are closely related to sustainable development. Thirdly, the comprehensive coordination analysis and measurement of a complex system only considers either the internal coordination of the inner-subsystems or the coordination among them. Due to the integrity of complex systems, this consideration is one-sided and unreasonable.

Table 1. The comparison between kinds of the coordination degree evaluation models.

\begin{tabular}{ccc}
\hline Category & Feature & Common Method \\
\hline Distance type & $\begin{array}{c}\text { Long-term, macroeconomic, } \\
\text { static, whole, complex }\end{array}$ & $\begin{array}{c}\text { Deviation coefficient method, membership } \\
\text { function method, gene coefficient method, set pair } \\
\text { analysis, data envelopment analysis and so on }\end{array}$ \\
\hline Change type & $\begin{array}{c}\text { Transient, dynamic, } \\
\text { local, complex }\end{array}$ & $\begin{array}{c}\text { Grey system model, differential } \\
\text { coefficient method and so on }\end{array}$ \\
\hline Integrated type & $\begin{array}{c}\text { Long-term, static, } \\
\text { whole, simple }\end{array}$ & $\begin{array}{c}\text { Geometric mean method, coupling } \\
\text { degree method and so on }\end{array}$ \\
\hline
\end{tabular}

It is important, therefore, to explore the mechanism of coordination, and to evaluate the coordination degree of CSR3ES in the context of sustainable development. In this paper, statistical and spatial analysis of the coordination of CSR3ES in 31 provinces and autonomous regions (PARs) in China were performed using data relevant to resources, environment, ecology, economy and society from the latest Statistical Yearbooks. The aim of this analysis is to identify the characteristics of the five subsystems, which are independent in concepts and correlated in development. Through analyzing the coordination of the inner-subsystem and inter-system, as well as the comprehensive coordination of CSR3ES, the weak links in the sustainable development of REEES in PARs were identified. Measures for improving the direction of development, and to provide a scientific basis for sustainable development are proposed.

\section{CSR3ES}

CSR3ES is an open, complicated and dynamic general system with a specific structure and certain functions. Figure 2 illustrates the subsystems of CSR3ES and their interactions. CSR3ES can be quantitatively described as:

$$
\begin{gathered}
C S_{R E E E S} \subseteq\left\{S_{1}, S_{2}, S_{3}, S_{4}, S_{5}, R_{a}, T\right\} \\
S_{i} \subseteq\left\{I_{i}, C_{i}, F_{i}\right\}, \quad i=1,2, \cdots, 5
\end{gathered}
$$

where $S_{1}, S_{2}, S_{3}, S_{4}$ and $S_{5}$ represent resources, environment, ecology, economy and society subsystem, respectively; $R_{a}$ is the relation system, i.e., a correction set in CSR3ES which includes various inter-subsystem correlations and inter-index correlations within the single subsystems. These complicated correlations are formed through direct inter-subsystem multi-correlations of the structures, or by relevant factors. They are characteristic of multi-directional effects and they have the basic attributes of diversity, interaction, hierarchy, dynamics, etc. [22-26]; $\mathrm{T}$ is time which embodies the time sequence of CSR3ES; $I_{i}, i=1,2, \ldots, 5$ are the indices of various subsystems (dynamic order parameters of complex systems); $C_{i}, i=1,2, \cdots, 5$ are the structures of various subsystems, respectively; and $F_{i}, i=1,2, \cdots, 5$ are the index calculating functions or methods of various subsystems, respectively. 


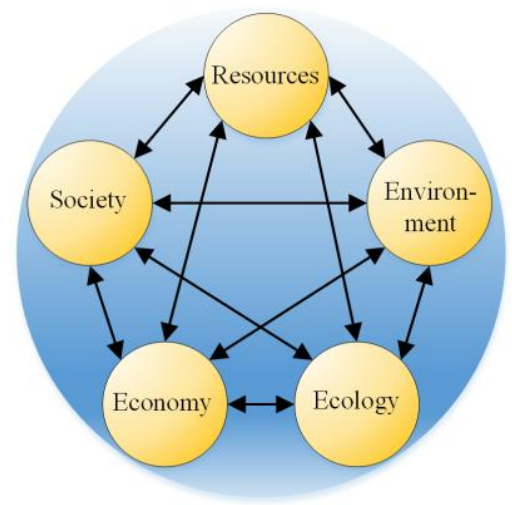

Figure 2. Subsystems of the complex system constituted by resources, environment, ecology, economy, and society subsystems (CSR3ES) and their interactions.

Research on CSR3ES aims to identify intrinsic links among its elements (subsystems). It is understood that, within a complex system, coordination is relative while incoordination is absolute, thus the ultimate objective of a complex system is overall optimization. The aim of investigating the coordination of CSR3ES is to strive to make coordinated relationships between resources, environment, ecology, economy and society; this will realize the objectives of CSR3ES and achieve the sustainable development of human society. This can be achieved by considering the inter-system interrelation and complicated coupling characteristics and, according to the idea of systematic coordination, by optimizing the overall design and achieving mutual coordination and collaboration between the subsystems [27-29].

\section{Data Preparation}

\subsection{Region Scale and Experimental Data}

In this study, by setting a province-level administrative region as a decision making unit (DMU), the experimental analysis on the coordination of CSR3ES was undertaken on a nationwide scale to master and control the macro coordination states of the REEES of various PARs. The index data for 31 PARs of China in 2013 were calculated using data derived from different sources. These included China Statistical Yearbook (2014) [30], China Statistical Yearbook on Environment (2014) [31], China Land and Resources Statistical Yearbook (2014) [32], China Water Conservancy Yearbook (2014) [33], Statistical Yearbooks (2014) of the PARs (excluding Hong Kong and Macao special administrative regions, and Taiwan Province), and other related survey data. All calculations were normalized and analyzed for the coordination of REEES.

\subsection{Index System Establishment}

Establishing the coordination analysis index system of CSR3ES is to define the dynamic order parameters $I_{i}, i=1,2, \cdots, 5$ of the complex system, which are quantitatively expressed in CSR3ES. Its main task, themed by the pursuit of the coordinated development of REEES, is to construct a set of operational and quantifiable evaluation methods to comprehensively reflect and quantitatively measure the coordinated development state and coordination degree in PARs across China.

Currently, there is no universal index selection criterion, and the index selection criteria and accuracy also vary with the specific monitoring and evaluation target, regional scale, etc. The index selection of CSR3ES, based on current research achievements on index selection, follows the traditional selection principles, such as operability, relative independence, instructive principles, comparability, etc. The index selection, due to the abstract concept and broad contents of CSR3ES, should also satisfy the following requirements according to the research scale and data collection of the present paper: 
(1) The selected indices should cover broad rather than detailed contents, and they should be able to describe and embody the status and changing trends of all related aspects (resources, environment, ecology, society, economy, etc.).

(2) The selected indices should be of high interest and popularity, easy to understand by decision makers, and easy to communicate to the public.

(3) The data used for index calculation should be reliable and accessible.

(4) It should be feasible to obtain important data for index calculation from collected data and documents.

(5) The comprehensive indices should be able to be employed to evaluate existing and emerging problems, diagnose factors causing the damages, and guide the formulation and implementation of policies and measures.

The hierarchical structure can not only easily describe the function dependency relationship between the subsystems, but also provide a convenient way to break down a complex system. Most importantly, it matches people's ideas in dealing with complicated affairs. Therefore, the subsystem structures $C_{i}, i=1,2, \cdots, 5$ in CSR3ES were all defined as hierarchical systems in the present paper. In reality, three to ten typical and representative indices are required for each hierarchical element.

Under the premise of the above requirements, the coordination analysis index system of CSR3ES was established by relying on five aspects: (1) analyzing the current resource utilization with the resource elements consisting of water, land and forest resources; (2) performing environmental carrying capacity analysis with the environmental elements constituted by environmental protection and environmental quality; (3) investigating basic status and restoration of the ecosystems with the ecological elements; (4) studying overall regional economic development and transportation network development, as well as potential developments, with the economic elements; and (5) studying social conditions and phenomena, and analyzing social development levels with the social elements.

The goal-criteria-index three-hierarchy index system of CSR3ES was established using the analytic hierarchy process (AHP) method (Figure 3). This reflects the interactions and mutual effects of the inter-elements within a subsystem and inter-subsystems of REEES, and it is convenient for the coordination evaluation of CSR3ES.

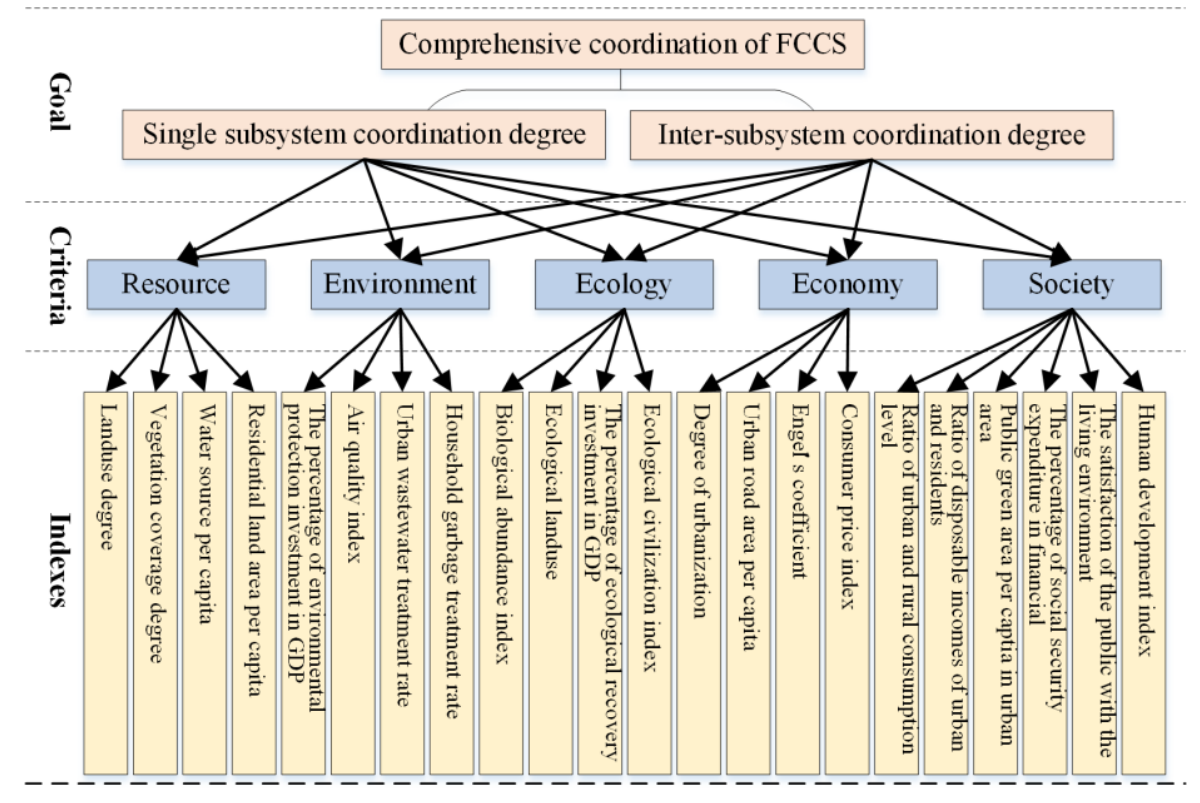

Figure 3. The index system of CSR3ES. 


\subsection{Data Normalization}

Since the effectiveness of selected indices for system coordination is not always unidirectional (indices that have positive effectiveness are called positive indices, and vice versa), some indices may go through a conversion of positive and negative effectiveness, especially with the variation of indices and the development of the complex system. The effectiveness of selected indices is positive when the index value approaches a specific value, and negative when they approach other specific values such as the consumer price index (CPI). These indices are called appropriate indices [7]. Before performing coordination analysis, therefore, the impact of dimension and magnitude differences of the index data must be eliminated by separately normalizing the positive, negative and moderate indices to achieve the communalities of evaluation indices.

Index data matrix of each subsystem $\left(S_{i}\right)$, composed of $n$ samples and $m_{i}$ indices (indices selected from subsystem $\left.S_{i}\right)$, is developed and expressed as $X_{i}=\left(x_{j k}\right)_{n \times m_{i}}$. The positive, negative and moderate indices can be obtained using Equation (2):

$$
\begin{gathered}
\text { Positive index : } x_{j k}^{\prime}=\frac{x_{j k}-\min x_{j k}}{\max x_{j k}-\min x_{j k}} \\
\text { Negative index : } x_{j k}^{\prime}=\frac{\max x_{j k}-x_{j k}}{\max x_{j k}-\min x_{j k}} \\
\text { Appropriate index : } \quad x_{j k}^{\prime}=1-\frac{\left|x_{j k}-x_{0 k}\right|}{\max \left|x_{j k}-x_{0 k}\right|}
\end{gathered}
$$

where $x_{j k}$ is the $k$ th index value of the $j$ th sample of subsystem $S_{i}$; and the $\max x_{j k}, \min x_{j k}$ and $x_{0 k}$ are the maximum, minimum and appropriate values of the $k$ th index of subsystem $S_{i}$, respectively.

\section{Research Methods}

To design the coordination degree calculation method of CSR3ES is to define the function $F_{i}, i=1,2, \cdots, 5$ of the quantitative expression model of CSR3ES. There are three types of coordination degree of CSR3ES: the coordination degree between the elements within a subsystem (termed the inner-subsystem coordination degree); those between the subsystems (termed the inter-subsystem coordination degree); and the comprehensive coordination degree, which is calculated from the previous two.

\subsection{Inner-Subsystem Coordination Degree}

Definition 1. Subsystem ideal coordination state. All the index values of a subsystem are the maximum values of a normalized data sample, and they are expressed by the vector: $X_{i}^{+}=\left(\max x_{j 1}, \max x_{j 2}, \cdots, \max x_{j m_{i}}\right)$.

Definition 2. Subsystem worst coordination state. All the index values of a subsystem are the minimum values of a normalized data sample, and they are expressed by the vector: $X_{i}^{-}=\left(\min x_{j 1}, \min x_{j 2}, \cdots, \min x_{j m_{i}}\right)$.

The inner-subsystem coordination degree, reflecting the coordination state of the indices in a subsystem, reflects the proximity of the subsystem to its ideal state as measured by distance or similarity [34,35]. The calculation steps of the inner-subsystem coordination degree are:

Step 1: Calculate the distances from sample subsystem $i$ to its optimal and worst coordination states, respectively. Adopt the Euclidean distances, i.e., $d_{i}^{+}$and $d_{i}^{-}$between samples and vectors $X_{i}^{+}$and $X_{i}^{-}$to express them, respectively (Equation (3)).

$$
d_{i}^{+}=\sqrt{\sum_{j=1}^{m_{i}}\left(x_{j k}^{\prime}-x_{j k}^{\prime+}\right)^{2}} ; d_{i}^{-}=\sqrt{\sum_{j=1}^{m_{i}}\left(x_{j k}^{\prime}-x_{j k}^{\prime}\right)^{2}}
$$


Step 2: Calculate the proximity of sample subsystem $i$ to its ideal coordination state, i.e., the coordination degree of sample subsystem $c d_{i}$ (Equation (4)).

$$
c d_{i}=\frac{d_{i}^{-}}{d_{i}^{+}+d_{i}^{-}}
$$

where $c d_{i} \in[0,1]$. When the mean values of all the indices within subsystem $i$ are at the maximum, $d_{i}^{+}=0$ and $d_{i}^{-}=1$, thus $c d_{i}=1$, this is the maximum value. This suggests that the sample subsystem is in the ideal state of coordination. When the mean values of all the indices within subsystem $i$ are at the minimum, $d_{i}^{+}=1$ and $d_{i}^{-}=0$, thus $c d_{i}=0$, this is the minimum value. This suggests that the sample subsystem is in its most uncoordinated state.

\subsection{Inter-System Coordination Degree}

Calculating the inter-system coordination degree is, in essence, calculating a multi-factor (subsystem indices) correlation analysis. In this paper, the DEA method was used to analyze inter-subsystem coordination from a macro point of view. In this method the subsystems, having balanced relationships, were regarded as the input and output of one another, and the 31 PARs were set as evaluated units and denoted by $\operatorname{DMU}_{n}(n=1,2, \cdots, 31)$ [8]. The inter-system coordination degree of CSR3ES is calculated by the following (Figure 4).

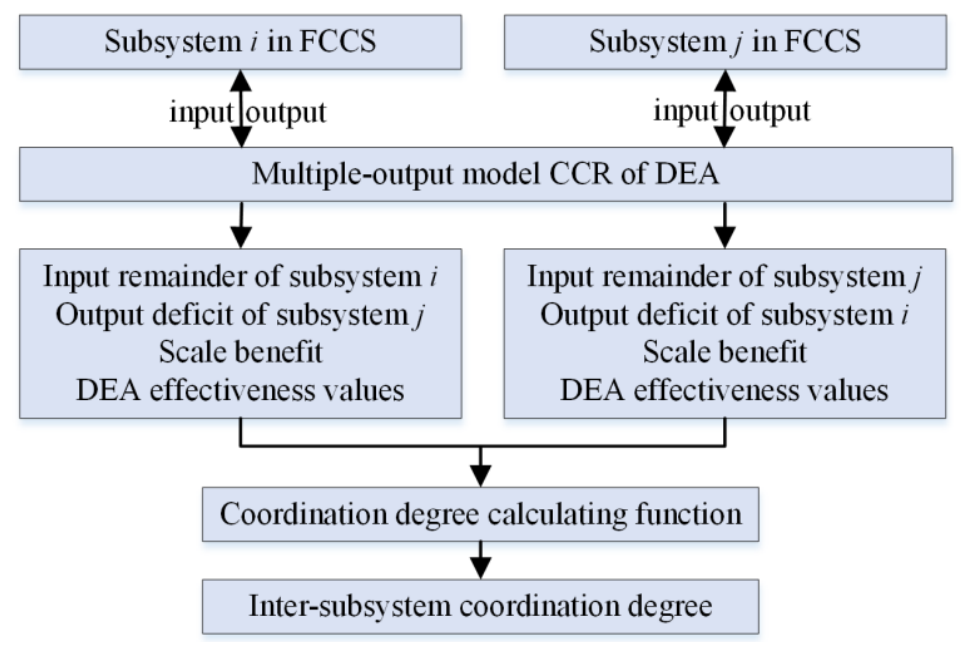

Figure 4. The calculation processes of the coordination degree between subsystems of CSR3ES.

Step 1: Selecting any two subsystems $i$ and $j$ which are the input and output of one another, and calculating the mutual input remainder and output deficit, scale benefits, and DEA effectiveness values, $\mu_{i}$ and $\mu_{j}$, using the CCR model of DEA.

Step 2: Establishing a coordination degree calculating function (Equation (5)):

$$
c d_{i j}=c d_{j i}=\min \left\{\mu_{i}, \mu_{j}\right\} / \max \left\{\mu_{i}, \mu_{j}\right\}
$$

The values of $\mu_{i}$ and $\mu_{j}$ are, the greater the value of $c d_{i j}$ becomes. This indicates a high coordination degree between the selected subsystems. When $\mu_{i}=\mu_{j}$ the two subsystems are in an ideal state of coordination. Conversely, if the values of $\mu_{i}$ and $\mu_{j}$ are vastly different, there will be a small value of $c d_{i j}$. The coordination degree therefore between the selected subsystems will be low.

\subsection{Comprehensive Coordination Degree of CSR3ES}

Integrity is an important principle of system theory. The overall effect, coupled by the interaction and interrelation between the subsystems of a complex system, is far beyond the summed function of individual elements. 
Defining $E_{i}$ as the effect of subsystem $i$ and TE as the total effect of the complex system will result in $T E=\sum E_{i}+\Delta E$, where $\Delta E$ is the coherent effect of inter-systems. $\Delta E>0$ suggests that a positive coherent effect will be exerted on the comprehensive coordination degree of the complex system through the inter-system synergistic effects, and vice versa [23].

Definition 3. Subsystem comprehensive coordination degree. This refers to the integrated coordination degree resulting from the interactions of various subsystems $S_{i}$, i.e., the summed effect of various subsystems of CSR3ES.

Definition 4. Inter-subsystems comprehensive coordination degree. This is introduced to measure the coherent effect of inter-systems, i.e., the summed coordination effect of inter-systems.

Definition 5. Comprehensive coordination degree of CSR3ES. This is a comprehensive index describing the overall state of the system coordination. Assuming that the state space and random state of CSR3ES are X and $x$, respectively, where $x \in X$, then, according to the definition, the coordination is actually a type of scalar function which describes the system state with the corresponding state, $x$, as:

$$
C D_{x}=f(x)
$$

where $C D_{x}$ is the system coordination degree under state $x$, i.e., the comprehensive coordination of CSR3ES CCS; and $f$ is a real function defined on $X$.

During this investigation, CSR3ES is always regarded as an organic integrity. The integrated function is not equal to a simple sum of the functions of different parts, but equal to that of every subsystem function plus the structural functions coming from subsystem interactions. In the principle of integrity, and assuming that the subsystem and inter-subsystem comprehensive coordinated development of REEES have equal effects on the integrated development of the complex system, the designed approach for coordination computation can be defined as:

$$
C D=\sqrt{C D_{1} \times C D_{2}}
$$

where $C D_{1}$ is the subsystem comprehensive coordination degree; and $C D_{2}$ is the inter-system comprehensive coordination degree. The calculation method for $C D_{1}$ is as follows (Figure 5):

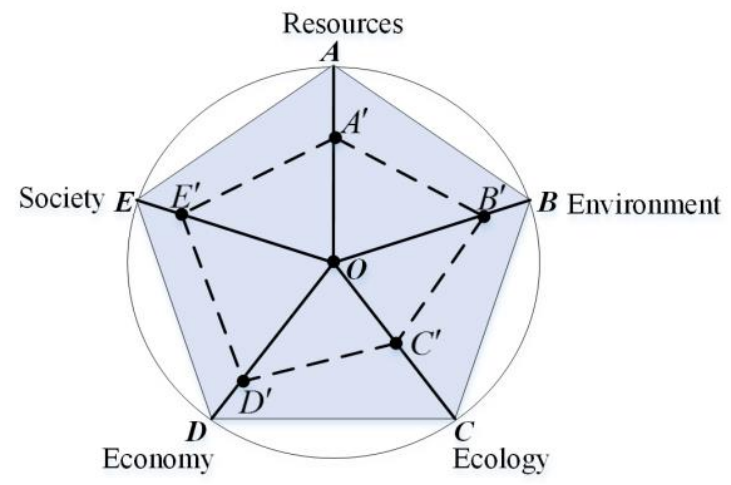

Figure 5. The calculation process of the subsystem comprehensive coordination degree.

Step 1: Draw a circle $O$ with a radius of 1 and a regular pentagon $A B C D E$ by setting resources, environment, ecology, economy and society as its vertices.

Step 2: Set the central point of circle $O$ as a starting point, and, based on the coordination degree level of subsystems, measure a corresponding length on lines $O A, O B, O C, O D$ and $O E$, respectively. Draw a new pentagon $A^{\prime} B^{\prime} C^{\prime} D^{\prime} E^{\prime}$ with the intersections $A^{\prime} B^{\prime} C^{\prime} D^{\prime}$ and $E^{\prime}$ as the vertices.

Step 3: The computing equation for the subsystem comprehensive coordination degree is:

$$
C D_{1}=\sqrt{S_{A^{\prime} B^{\prime} C^{\prime} D^{\prime} E^{\prime}} / S_{A B C D E}}
$$


where $S_{A B C D E}$ and $S_{A^{\prime} B^{\prime} C^{\prime} D^{\prime} E^{\prime}}$ are the areas of pentagons $A B C D E$ and $A^{\prime} B^{\prime} C^{\prime} D^{\prime} E^{\prime}$, respectively; $C D_{1} \in[0,1]$. When $S_{A^{\prime} B^{\prime} C^{\prime} D^{\prime} E^{\prime}}=S_{A B C D E}$, that is, the coordination degrees of all subsystems are equal to 1 , the subsystem comprehensive coordination degree $C D_{1}=1$, and all the subsystems are in an ideal state of coordination.

Similarly, the inter-system comprehensive coordination degree $\left(C D_{2}\right)$ is calculated by establishing a regular decagon via pair-wise combinations of resources, environment, ecology, economy and society. This is followed by the construction of a corresponding decagon based on the inter-system coordination degrees of all the subsystems. The square root of the areas ratio of these two decagons is the inter-system comprehensive coordination degree.

\subsection{Coordination Management of CSR3ES}

Definition 6. Coordination management of CSR3ES. Assuming that the current and expected states of coordination of CSR3ES are denoted by $x_{0}$ and $x_{t}$, respectively, the state transition process $\left(x_{0} \rightarrow x_{t}\right)$, which is achieved through control, adjustment and optimization, will be referred to as coordination management.

The methods and strategies for specific control, adjustment and optimization will be judged and determined by the calculated coordination degrees. According to the timing characteristics of CSR3ES, the inner-subsystem and inter-subsystem coordination degrees and comprehensive coordination degree at different stages were determined and analyzed to guide the restoration and improvement of the subsequent coordinated development of CSR3ES, as well as the decision-making process [36] (Figure 6).

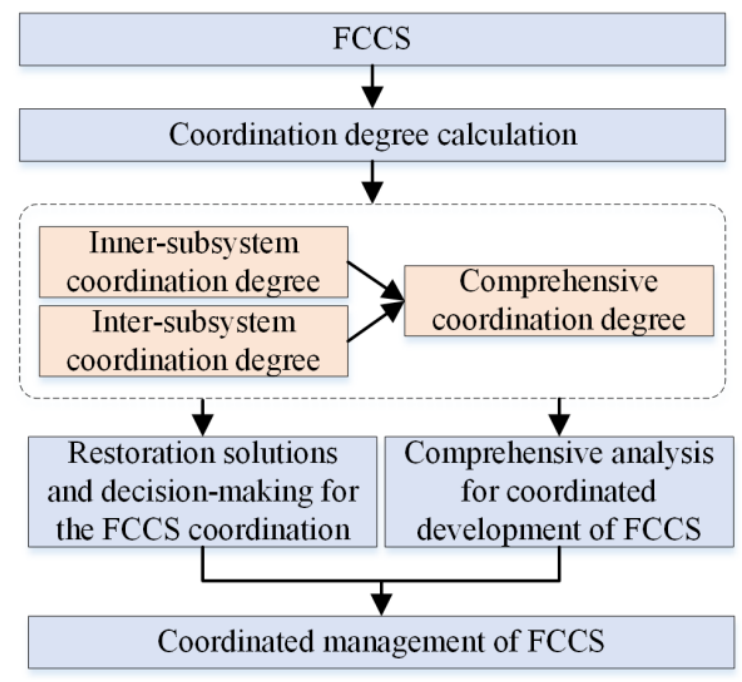

Figure 6. The framework for the coordination management of CSR3ES.

\section{Result Analyses}

\subsection{Analyzing Subsystem Coordination Degree of PARs}

Based on the normalized data and the designed calculation methods in this paper, the inner-subsystem coordination degree and subsystem comprehensive coordination degree for 31 PARs in China in 2013 are determined and shown in Table 2. The larger values in Table 2 reflect higher levels of coordination, and vice versa. By using Excel and ArcGIS 10.2 (Esri, California, CA, USA), Radar charts of the inner-subsystem coordination degree (Figure 7) and spatial distribution grade map of comprehensive coordination degree (Figure 8) are presented. As shown in Figure 8, the darker the region color, the higher the coordination degree. 


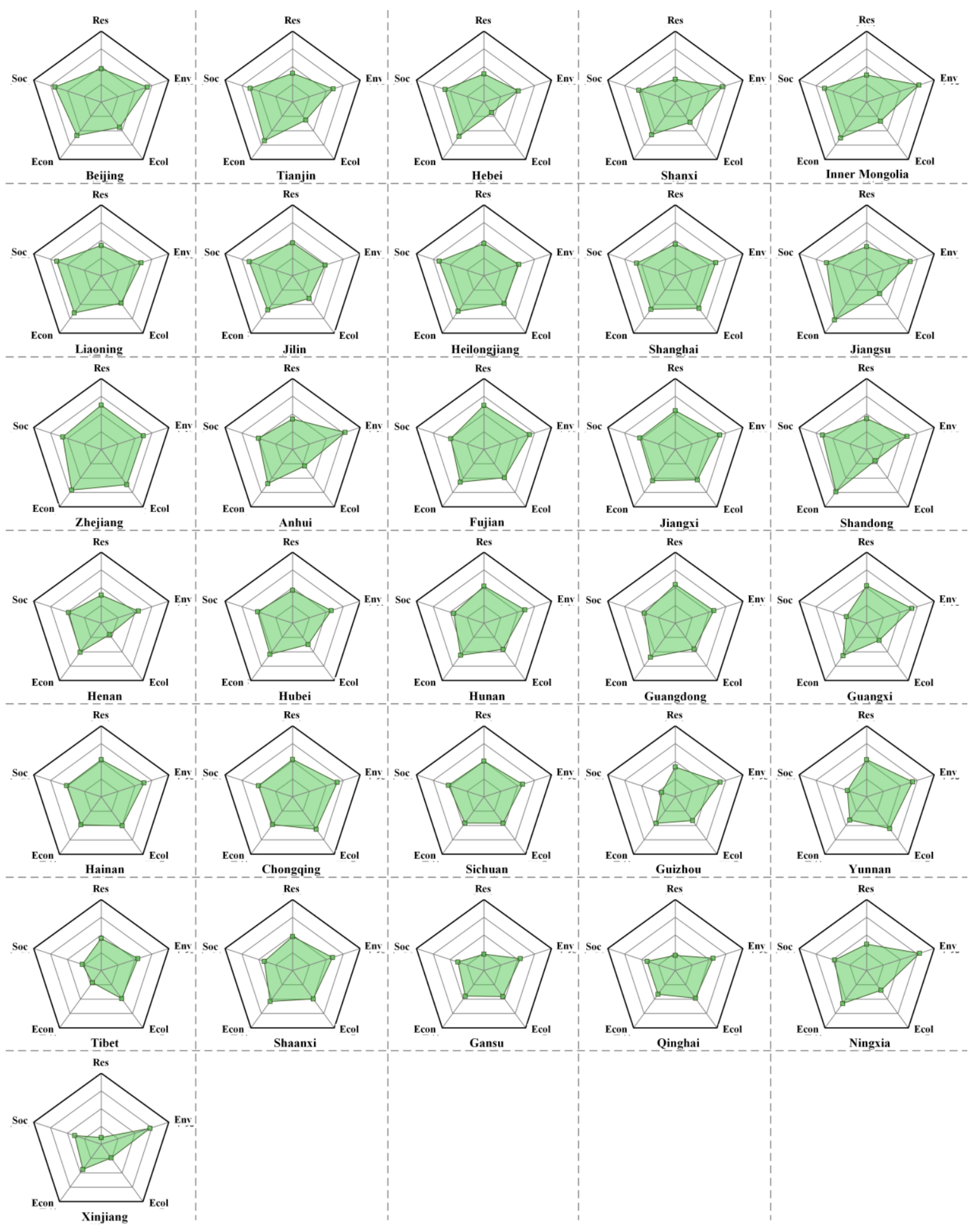

Figure 7. Radar charts of the subsystem coordination degree of 31 provinces and autonomous regions (PARs) in China, 2013. 


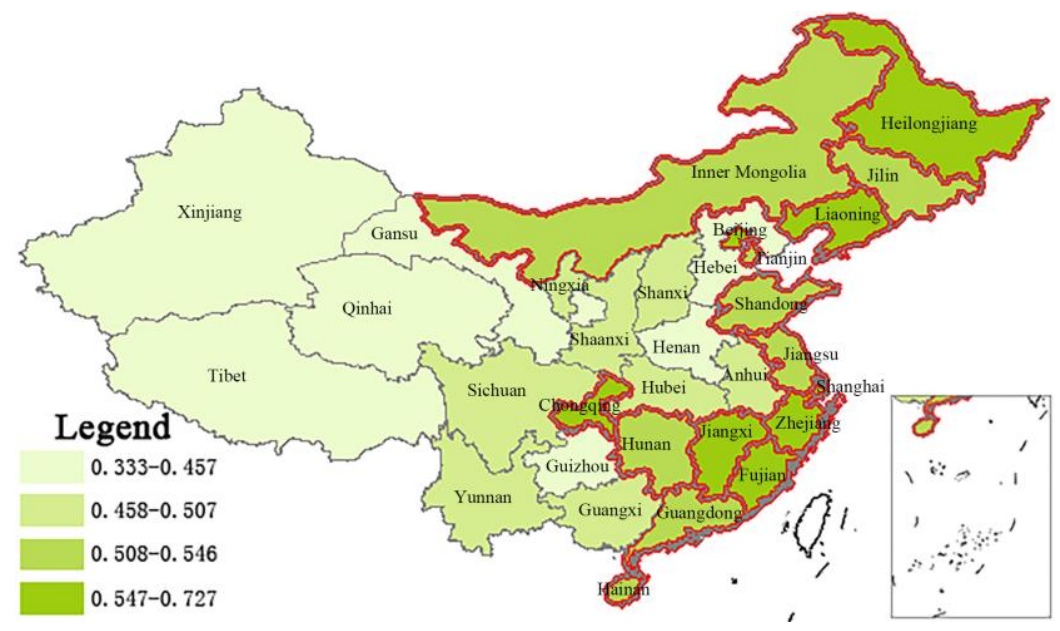

Figure 8. A spatial distribution grade map of comprehensive coordination degrees of 31 PARs in China, 2013.

Table 2. Inner-subsystem coordination degree and subsystem comprehensive coordination degree (CCD) of 31 PARs in China, 2013.

\begin{tabular}{ccccccc}
\hline PARs & Res & Env & Ecol & Econ & Soc & CCD \\
\hline Beijing & 0.4699 & 0.6815 & 0.4403 & 0.5831 & 0.6858 & 0.5655 \\
Tianjin & 0.4043 & 0.6015 & 0.3148 & 0.6743 & 0.6283 & 0.5143 \\
Hebei & 0.3963 & 0.5086 & 0.1840 & 0.5974 & 0.5764 & 0.4423 \\
Shanxi & 0.3203 & 0.6975 & 0.3536 & 0.5688 & 0.5400 & 0.4799 \\
Inner Mongolia & 0.3796 & 0.7745 & 0.3332 & 0.6250 & 0.6237 & 0.5267 \\
Liaoning & 0.4266 & 0.5909 & 0.4776 & 0.6468 & 0.6578 & 0.5566 \\
Jilin & 0.4635 & 0.4816 & 0.3961 & 0.5964 & 0.6424 & 0.5159 \\
Heilongjiang & 0.4531 & 0.5172 & 0.4860 & 0.6177 & 0.6647 & 0.5473 \\
Shanghai & 0.4437 & 0.5985 & 0.5683 & 0.5847 & 0.5731 & 0.5527 \\
Jiangsu & 0.4104 & 0.6457 & 0.3126 & 0.7715 & 0.5939 & 0.5310 \\
Zhejiang & 0.6242 & 0.6231 & 0.6138 & 0.7070 & 0.5702 & 0.6268 \\
Anhui & 0.4284 & 0.7782 & 0.2886 & 0.5946 & 0.5051 & 0.4993 \\
Fujian & 0.6206 & 0.6756 & 0.4916 & 0.5691 & 0.4920 & 0.5686 \\
Jiangxi & 0.5456 & 0.6576 & 0.5303 & 0.5458 & 0.5254 & 0.5604 \\
Shandong & 0.4332 & 0.5975 & 0.1983 & 0.7384 & 0.655 & 0.5081 \\
Henan & 0.3937 & 0.5499 & 0.2006 & 0.5060 & 0.4849 & 0.4158 \\
Hubei & 0.4631 & 0.5714 & 0.3725 & 0.5438 & 0.5188 & 0.4904 \\
Hunan & 0.5210 & 0.6051 & 0.4573 & 0.5594 & 0.4468 & 0.5158 \\
Guangdong & 0.5436 & 0.5696 & 0.4497 & 0.5939 & 0.458 & 0.5204 \\
Guangxi & 0.5271 & 0.6686 & 0.2998 & 0.5670 & 0.2992 & 0.4583 \\
Hainan & 0.5225 & 0.6324 & 0.5037 & 0.4868 & 0.5124 & 0.5313 \\
Chongqing & 0.5263 & 0.6618 & 0.5653 & 0.4827 & 0.5062 & 0.5488 \\
Sichuan & 0.5030 & 0.5721 & 0.4592 & 0.4569 & 0.5256 & 0.5029 \\
Guizhou & 0.4190 & 0.6635 & 0.4132 & 0.4621 & 0.202 & 0.4292 \\
Yunnan & 0.5228 & 0.6797 & 0.5519 & 0.4044 & 0.2853 & 0.4937 \\
Tibet & 0.4527 & 0.5428 & 0.4905 & 0.2120 & 0.2793 & 0.4004 \\
Shaanxi & 0.4791 & 0.5914 & 0.4959 & 0.5391 & 0.4189 & 0.5041 \\
Gansu & 0.2300 & 0.5394 & 0.4535 & 0.4454 & 0.3856 & 0.4077 \\
Qinghai & 0.2127 & 0.5585 & 0.4838 & 0.4142 & 0.4183 & 0.4127 \\
Ningxia & 0.3702 & 0.7826 & 0.3448 & 0.5752 & 0.4762 & 0.4915 \\
Xinjiang & 0.0938 & 0.7235 & 0.2389 & 0.4391 & 0.3933 & 0.3333 \\
\hline
\end{tabular}

Res represents Resource, Env represents Environment, Ecol represents Ecology, Econ represents Economy, and Soc represents Society, similarly hereinafter. 
(1) The top and bottom ten PARs of the inner-subsystem coordination of REEES in China in 2013 are shown in Table 3 . The inner-subsystem coordination degree of resources and ecology are ranked first in Zhejiang, which verify the remarkable achievements in forming the space pattern, industrial structure, mode of production, life of saving resources and protecting the ecology in Zhejiang. From the initiation of Centurial Trip of Chinese Environmental Protection In Ningxia in 2005 till now, It has played a very good role in promoting supervision for Ningxia's environmental protection; Jiangsu's comprehensive economic strength has been in the forefront of China. The inner-subsystem coordination degree of society is ranked first in Beijing. As the measures of steady growth, promoting reform, structural adjustment and benefit of people's livelihood are implemented, social harmony, stability and healthy development are promoted. Although Xinjiang is rich in land resources, there are serious problems in land use and forest coverage, which leads to a large amount of waste of resources. Most of the bottom ten PARs of the inner-subsystem coordination of economy and society subsystems are the same, which fully shows that the main factors that affect harmonious social stability in China are mainly derived from economic development. The disparity between the rich and the poor caused by too fast or too slow growth has aggravated social instability.

Table 3. The top and bottom ten PARs of the inner-subsystem coordination of REEES of China, 2013.

\begin{tabular}{|c|c|c|}
\hline Subsystem & Top Ten & Bottom Ten \\
\hline Resources & $\begin{array}{c}\text { Zhejiang, Fujian, Jiangxi, Guangdong, } \\
\text { Guangxi, Chongqing, Yunnan, } \\
\text { Hainan, Hunan, Sichuan }\end{array}$ & $\begin{array}{l}\text { Jiangsu, Tianjin, Hebei, Henan, } \\
\text { Inner Mongolia, Ningxia, Shanxi, } \\
\text { Gansu, Qinghai, Xinjiang }\end{array}$ \\
\hline Environment & $\begin{array}{l}\text { Ningxia, Anhui, Inner Mongolia, } \\
\text { Xinjiang, Shanxi, Beijing, Yunnan, } \\
\text { Fujian, Guangxi, Guizhou }\end{array}$ & $\begin{array}{c}\text { Sichuan, Hubei, Guangdong, Qinghai, } \\
\text { Henan, Tibet, Gansu, } \\
\text { Heilongjiang, Hebei, Jilin }\end{array}$ \\
\hline Ecology & $\begin{array}{l}\text { Zhejiang, Shanghai, Chongqing, } \\
\text { Yunnan, Jiangxi, Hainan, Shaanxi, } \\
\text { Fujian, Tibet, Heilongjiang }\end{array}$ & $\begin{array}{c}\text { Ningxia, Inner Mongolia, Tianjin, } \\
\text { Jiangsu, Guangxi, Anhui, Xinjiang, } \\
\text { Henan, Shandong, Hebei }\end{array}$ \\
\hline Economy & $\begin{array}{l}\text { Jiangsu, Shandong, Zhejiang, Tianjin, } \\
\text { Liaoning, Inner Mongolia, Heilongjiang, } \\
\text { Hebei, Jilin, Anhui }\end{array}$ & $\begin{array}{c}\text { Henan, Hainan, Chongqing, Guizhou, } \\
\text { Sichuan, Gansu, Xinjiang, Qinghai, } \\
\text { Yunnan, Tibet }\end{array}$ \\
\hline Society & $\begin{array}{c}\text { Beijing, Heilongjiang, Liaoning, } \\
\text { Shandong, Jilin, Tianjin, Inner Mongolia, } \\
\text { Jiangsu, Hebei, Shanghai }\end{array}$ & $\begin{array}{c}\text { Guangdong, Hunan, Shaanxi, Qinghai, } \\
\text { Xinjiang, Gansu, Guangxi, Yunnan, } \\
\text { Tibet, Guizhou }\end{array}$ \\
\hline
\end{tabular}

(2) To sum up the state of coordination of PARs, the coordinated development of the ecology subsystem is the worst in China, followed by resources and society subsystems. The inner-subsystem coordination of environment and economy is in an ideal state. The economic development in China has gradually stabilized and coordinated, and the environment has recently significantly improved due to the enhancement of environmental awareness, an emphasis on environmental protection, and increasing inputs in environmental control. In the future, focus should gradually shift to the recovery and adjustment of the ecological subsystem, to efficient resource utilization, as well as fair, just and coordinated social development.

(3) The inner-subsystem coordinated development of ecology and resources is in a relatively poor state in most PARs, such as in Beijing, Tianjin, Hebei, Shanxi, Inner Mongolia, Liaoning, Jiangsu, Anhui, Shandong, Henan, Hubei and Ningxia. The regions that show a relatively balanced subsystem development include Shanghai, Zhejiang, Jiangxi, Hainan, Chongqing and Sichuan, and those indicating an imbalanced subsystem development include Hebei, Henan, Guangxi, Guizhou, Tibet, Gansu, Qinghai and Xinjiang.

(4) The subsystem comprehensive coordination degree of PARs in China is generally relatively low. The PARs areas with a relatively coordinated development includes Zhejiang, Fujian, Beijing, Jiangxi, Liaoning, Shanghai, Chongqing and Heilongjiang, and PARs areas with an uncoordinated development 
include Hebei, Guizhou, Henan, Qinghai, Gansu, Tibet and Xinjiang. The coordinated development regions present a half-circle pattern, which is characterized by the coastal PARs encircling from the north, east and south (the regions within the red lines in Figure 8). The central and western regions belong to the PARs areas that have regions with a relatively low-level of coordinated development. Although Chongqing and Hunan have the potential to increase their level of development, no obvious core-peripheral spatial structure mode has taken shape.

(5) Based on similarities in the inter-subsystem coordinated development patterns (Figure 7), the PARs can be divided into eight groups: Group 1: Tianjin, Hebei, Shanxi, Inner Mongolia, Jiangsu, Anhui, Shandong, Henan and Ningxia; Group 2: Beijing, Liaoning, Jilin and Heilongjiang; Group 3: Zhejiang, Fujian, Hubei, Hunan, Guangdong and Jiangxi; Group 4: Shanghai, Hainan, Chongqing, Sichuan and Shaanxi; Group 5: Guangxi and Guizhou; Group6: Yunnan and Tibet; Group 7: Gansu and Qinghai; and Group 8: Xinjiang, which is separated from other PARs in view of its specific coordinated development pattern. It can be seen from the spatial distribution grade map (Figure 9) that the distribution of PARs with similar development patterns is not random, their distribution is characteristic of a strong spatial dependence; that is, PARs with similar patterns tend to be adjacent to each other. It explains the region correlation of the coordinated development.

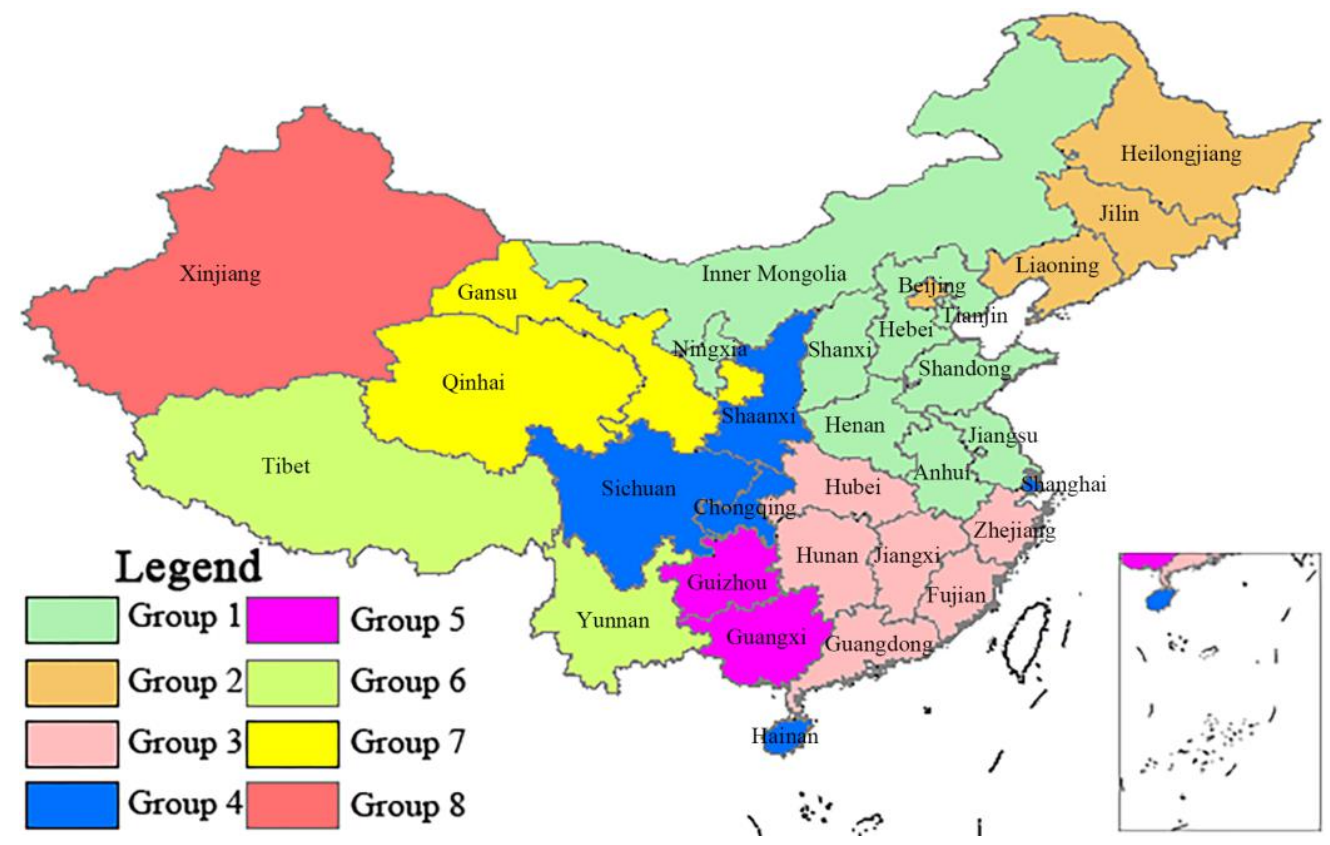

Figure 9. Spatial correlation analysis of regions with similar inter-subsystem coordinated development patterns.

\subsection{Analysis of Inter-Subsystem Coordination Degrees of PARs}

Similarly, based on the normalized data and the designed calculation methods in this paper, the inter-subsystem coordination degrees and the inter-subsystem comprehensive coordination degrees of PARs in China in 2013 are shown in Table 4. The larger the values in the table, the higher the coordination levels, and vice versa. By using Excel and ArcGIS 10.2, Radar charts of the inter-subsystem coordination degrees (Figure 10) and a spatial distribution grade map of comprehensive coordination degrees (Figure 11) are shown. As seen in Figure 11, the darker the color, the higher the coordination degree. 


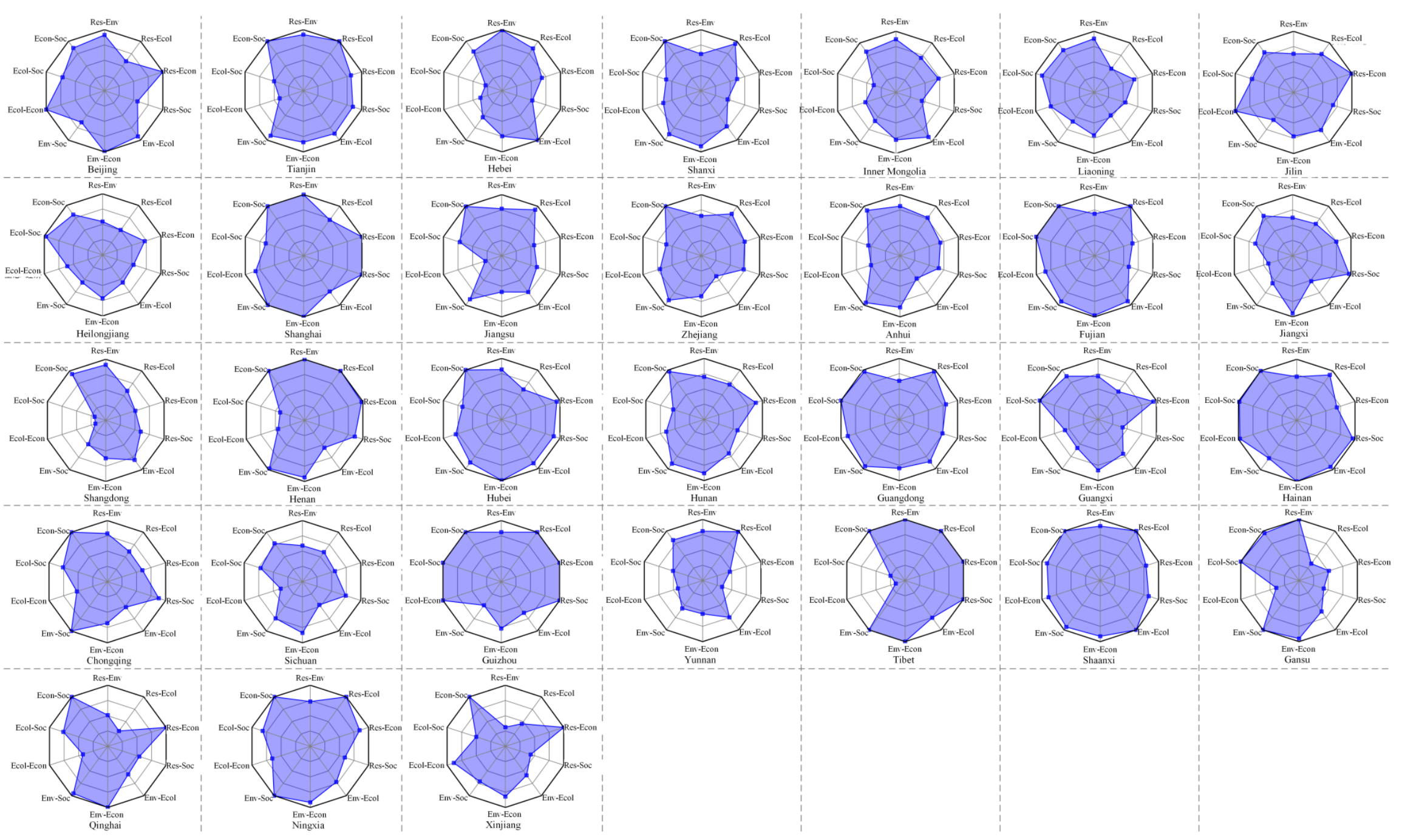

Figure 10. Radar charts of the inter-subsystem coordination degree for 31 PARs in China, 2013. 
Table 4. Inter-subsystem coordination degree and the inter-subsystem comprehensive coordination degree (CCD) for 31 PARs in China, 2013.

\begin{tabular}{|c|c|c|c|c|c|c|c|c|c|c|c|}
\hline PARs & Res-Env & Res-Ecol & Res-Econ & Res-Soc & Env-Ecol & Env-Econ & Env-Soc & Ecol-Econ & Ecol-Soc & Econ-Soc & CCD \\
\hline Beijing & 0.9134 & 0.5977 & 1.0000 & 0.5656 & 0.9256 & 1.0000 & 0.6379 & 1.0000 & 0.7176 & 0.8659 & 0.8102 \\
\hline Tianjin & 0.9199 & 1.0000 & 0.8176 & 0.8501 & 0.8683 & 0.8429 & 0.9099 & 0.4057 & 0.5010 & 1.0000 & 0.8163 \\
\hline Hebei & 0.9923 & 0.8566 & 0.6826 & 0.5179 & 1.0000 & 0.7446 & 0.5385 & 0.3721 & 0.2832 & 0.7938 & 0.6907 \\
\hline Shanxi & 0.6038 & 0.9509 & 0.6220 & 0.4581 & 0.7190 & 0.9093 & 0.8798 & 0.6464 & 0.5967 & 1.0000 & 0.7341 \\
\hline Inner Mongolia & 0.8701 & 0.6983 & 0.7304 & 0.4463 & 0.9053 & 0.7761 & 0.5795 & 0.5229 & 0.3798 & 0.8238 & 0.6731 \\
\hline Liaoning & 0.8808 & 0.4808 & 0.6902 & 0.5383 & 0.4652 & 0.7034 & 0.5907 & 0.7414 & 0.8901 & 0.8544 & 0.6878 \\
\hline Jilin & 0.6332 & 0.7779 & 0.9941 & 0.6774 & 0.7655 & 0.7194 & 0.5574 & 0.9937 & 0.7097 & 0.8107 & 0.7587 \\
\hline Heilongjiang & 0.5452 & 0.5034 & 0.7237 & 0.5315 & 0.5605 & 0.7121 & 0.5605 & 0.6048 & 0.9700 & 0.8141 & 0.6541 \\
\hline Shanghai & 1.0000 & 0.7246 & 1.0000 & 1.0000 & 0.7242 & 1.0000 & 1.0000 & 0.8239 & 0.6494 & 1.0000 & 0.8892 \\
\hline Jiangsu & 0.7692 & 0.9292 & 0.5552 & 0.6035 & 0.7366 & 0.5943 & 0.8812 & 0.2801 & 0.7183 & 0.9962 & 0.7001 \\
\hline Zhejiang & 0.6526 & 0.8469 & 0.7453 & 0.7288 & 0.4161 & 0.6651 & 0.9000 & 0.7071 & 0.5997 & 1.0000 & 0.7224 \\
\hline Anhui & 0.8119 & 0.7693 & 0.6914 & 0.6634 & 0.4607 & 0.8460 & 0.9508 & 0.4975 & 0.5423 & 0.9166 & 0.7141 \\
\hline Fujian & 0.6867 & 1.0000 & 0.6496 & 0.5884 & 0.9218 & 0.9782 & 0.9258 & 0.8426 & 1.0000 & 1.0000 & 0.8590 \\
\hline Jiangxi & 0.6225 & 0.6448 & 0.7484 & 0.9684 & 0.5174 & 0.9452 & 0.5571 & 0.4171 & 0.6387 & 0.8072 & 0.6813 \\
\hline Shandong & 0.9090 & 0.5966 & 0.5072 & 0.6012 & 0.8005 & 0.6223 & 0.4833 & 0.1768 & 0.1907 & 0.9350 & 0.5981 \\
\hline Henan & 1.0000 & 1.0000 & 0.9775 & 0.8620 & 0.5528 & 0.9352 & 0.9762 & 0.4531 & 0.4188 & 1.0000 & 0.8232 \\
\hline Hubei & 0.8172 & 0.6072 & 0.9461 & 0.8932 & 0.8851 & 0.9976 & 0.8723 & 0.7853 & 0.6718 & 1.0000 & 0.8462 \\
\hline Hunan & 0.6974 & 0.7079 & 0.8866 & 0.5727 & 0.6877 & 0.8802 & 0.8937 & 0.6494 & 0.5302 & 0.9708 & 0.7437 \\
\hline Guangdong & 0.6328 & 0.9696 & 0.8007 & 0.7411 & 0.8519 & 0.7985 & 0.9493 & 0.8823 & 1.0000 & 0.9661 & 0.8573 \\
\hline Guangxi & 0.7079 & 0.5646 & 0.9485 & 0.4215 & 0.6960 & 0.8335 & 0.5771 & 0.5679 & 1.0000 & 0.8746 & 0.7127 \\
\hline Hainan & 0.7142 & 0.9187 & 0.6889 & 0.9602 & 0.9417 & 1.0000 & 0.7694 & 0.9729 & 0.9837 & 1.0000 & 0.8927 \\
\hline Chongqing & 0.7887 & 0.6089 & 0.6021 & 0.8829 & 0.5167 & 0.6800 & 1.0000 & 0.5222 & 0.7602 & 1.0000 & 0.7303 \\
\hline Sichuan & 0.5900 & 0.5976 & 0.5580 & 0.7429 & 0.4708 & 0.8396 & 0.7446 & 0.3742 & 0.7164 & 0.7756 & 0.6349 \\
\hline Guizhou & 0.8096 & 1.0000 & 1.0000 & 1.0000 & 0.6311 & 0.7685 & 0.4782 & 1.0000 & 1.0000 & 1.0000 & 0.8707 \\
\hline Yunnan & 0.8076 & 0.9865 & 0.4677 & 0.3345 & 0.7465 & 0.5460 & 0.5663 & 0.4228 & 0.5060 & 0.8193 & 0.6254 \\
\hline Tibet & 1.0000 & 1.0000 & 1.0000 & 1.0000 & 0.7549 & 1.0000 & 1.0000 & 0.1591 & 0.2494 & 1.0000 & 0.8341 \\
\hline Shaanxi & 0.8919 & 1.0000 & 0.7875 & 0.8317 & 1.0000 & 0.9141 & 0.9408 & 0.8855 & 0.9118 & 0.9989 & 0.9155 \\
\hline Gansu & 1.0000 & 0.3420 & 0.5120 & 0.4253 & 0.6264 & 0.9513 & 1.0000 & 0.3904 & 1.0000 & 0.9592 & 0.7244 \\
\hline Qinghai & 0.5088 & 0.3091 & 1.0000 & 0.5413 & 0.5683 & 1.0000 & 0.9532 & 0.4253 & 0.7620 & 1.0000 & 0.6955 \\
\hline Ningxia & 0.7327 & 1.0000 & 0.8467 & 0.5931 & 0.7224 & 0.9192 & 1.0000 & 0.6509 & 0.8159 & 1.0000 & 0.8261 \\
\hline Xinjiang & 0.3136 & 0.4555 & 1.0000 & 0.4347 & 0.5875 & 0.8234 & 0.7111 & 0.8833 & 0.4989 & 1.0000 & 0.6511 \\
\hline
\end{tabular}

Res-Env represents Resource-Environment, Res-Ecol represents Resource-Ecology, Res-Econ represents Resource-Economy, Res-Soc represents Resource-Society, Env-Ecol represents Environment-Ecology, Env-Econ represents Environment-Economy, Env-Soc represents Environment-Society, Ecol-Econ represents Ecology-Economy, Ecol-Soc represents Ecology-Society, Econ-Soc represents Economy-Society, similarly hereinafter. 


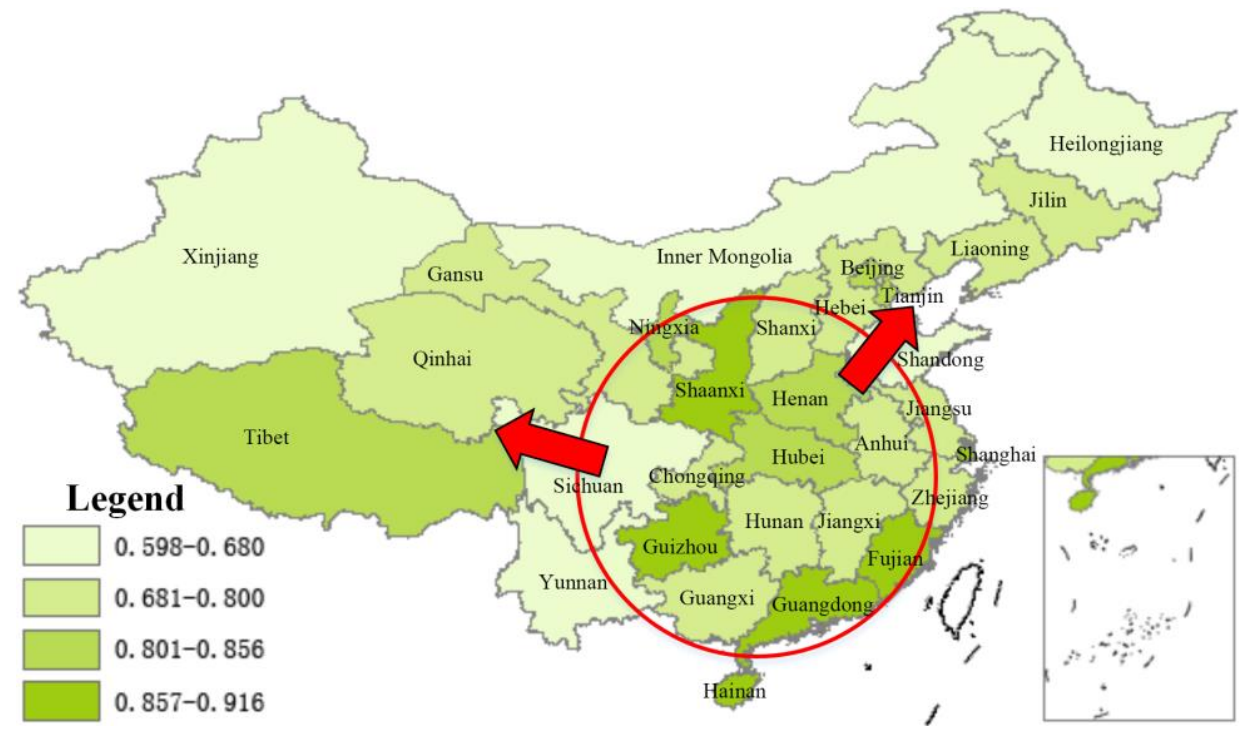

Figure 11. A spatial distribution grade map of the inter-subsystem comprehensive coordination degree for 31 PARs in China, 2013.

(1) The top and bottom ten PARs of the inter-subsystem coordination of REEES in China during 2013 are shown in Table 5.

Table 5. The top and bottom ten PARs of inter-subsystem coordination of REEES for China, 2013.

\begin{tabular}{|c|c|c|}
\hline Inter-Subsystem & Top Ten & Bottom Ten \\
\hline Resource-Environment & $\begin{array}{l}\text { Shanghai, Henan, Tibet, Gansu, Hebei, } \\
\text { Tianjin, Beijing, Shandong, } \\
\text { Shaanxi, Liaoning }\end{array}$ & $\begin{array}{c}\text { Fujian, Zhejiang, Jilin, Guangdong, } \\
\text { Jiangxi, Shanxi, Sichuan, Heilongjiang, } \\
\text { Qinghai, Xinjiang }\end{array}$ \\
\hline Resource-Ecology & $\begin{array}{l}\text { Tianjin, Fujian, Henan, Guizhou, Tibet, } \\
\text { Shaanxi, Ningxia, Yunnan, } \\
\text { Guangdong, Shanxi }\end{array}$ & $\begin{array}{l}\text { Hubei, Beijing, Sichuan, Shandong, } \\
\text { Guangxi, Heilongijiang, Liaoning, } \\
\text { Xinjiang, Gansu, Qinghai }\end{array}$ \\
\hline Resource-Economy & $\begin{array}{l}\text { Beijing, Shanghai, Guizhou, Tibet, } \\
\text { Qinghai, Xinjiang, Jilin, Henan, } \\
\text { Guangxi, Hubei }\end{array}$ & $\begin{array}{l}\text { Hainan, Hebei, Fujian, Shanxi, } \\
\text { Chongqing, Sichuan, Jiangsu, Gansu, } \\
\text { Shandong, Yunnan }\end{array}$ \\
\hline Resource-Society & $\begin{array}{l}\text { Shanghai, Guizhou, Tibet, Jiangxi, } \\
\text { Hainan, Hubei, Chongqing, Henan, } \\
\text { Tianjin, Shaanxi }\end{array}$ & $\begin{array}{l}\text { Qinghai, Liaoning, Heilongjiang, Hebei, } \\
\text { Shanxi, Inner Mongolia, Xinjiang, } \\
\text { Gansu, Guangxi, Yunnan }\end{array}$ \\
\hline Environment-Ecology & $\begin{array}{l}\text { Hebei, Shaanxi, Hainan, Beijing, Fujian, } \\
\text { Inner Mongolia, Hubei, Tianjin, } \\
\text { Guangdong, Shandong }\end{array}$ & $\begin{array}{c}\text { Xinjiang, Qinghai, Heilongjiang, Henan, } \\
\text { Jiangxi, Chongqing, Sichuan, Liaoning, } \\
\text { Anhui, Zhejiang }\end{array}$ \\
\hline Environment-Economy & $\begin{array}{l}\text { Beijing, Shanghai, Hainan, Tibet, } \\
\text { Qinghai, Hubei, Fujian, Gansu, } \\
\text { Jiangxi, Henan }\end{array}$ & $\begin{array}{l}\text { Guizhou, Hebei, Jilin, Heilongjiang, } \\
\text { Liaoning, Chongqing, Zhejiang, } \\
\text { Shandong, Jiangsu, Yunnan }\end{array}$ \\
\hline Environment-Society & $\begin{array}{c}\text { Shanghai, Chongqing, Tibet, Gansu, } \\
\text { Ningxia, Henan, Qinghai, Anhui, } \\
\text { Guangdong, Shaanxi }\end{array}$ & $\begin{array}{l}\text { Liaoning, Inner Mongolia, Guangxi, } \\
\text { Yunnan, Heilongjiang, Jilin, Jiangxi, } \\
\text { Hebei, Shandong, Guizhou }\end{array}$ \\
\hline Ecology-Economy & $\begin{array}{c}\text { Beijing, Guizhou, Jilin, Hainan, Shaanxi, } \\
\text { Xinjiang, Guangdong, Fujian, } \\
\text { Shanghai, Hubei }\end{array}$ & $\begin{array}{l}\text { Qinghai, Yunnan, Jiangxi, Tianjin, } \\
\text { Gansu, Sichuan, Hebei, Jiangsu, } \\
\text { Shandong, Tibet }\end{array}$ \\
\hline Ecology-Society & $\begin{array}{l}\text { Fujian, Guangdong, Guangxi, Guizhou, } \\
\text { Gansu, Hainan, Heilongjiang, Shaanxi, } \\
\text { Liaoning, Ningxia }\end{array}$ & $\begin{array}{l}\text { Anhui, Hunan, Yunnan, Tianjin, } \\
\text { Xinjiang, Henan, Inner Mongolia, Hebei, } \\
\text { Tibet, Shandong }\end{array}$ \\
\hline Economy-Society & $\begin{array}{l}\text { Tianjin, Shanxi, Shanghai, Zhejiang, } \\
\text { Fujian, Henan, Hubei, Hainan, } \\
\text { Chongqing, Guizhou }\end{array}$ & $\begin{array}{l}\text { Guangxi, Beijing, Liaoning, Inner } \\
\text { Mongolia, Yunnan, Heilongjiang, Jilin, } \\
\text { Jiangxi, Hebei, Sichuan }\end{array}$ \\
\hline
\end{tabular}


(2) In summary, for the inter-subsystem state of coordination, the coordinated development of ecology-economy, ecology-society and resource-society is not ideal; the environment-ecology subsystem is optimal. Shanghai, Fujian, Hubei, Guangdong, Hainan and Shaanxi are regions where the development of the inter-subsystems is relatively balanced, and Jiangxi, Shandong, Sichuan, Yunnan, Gansu, Qinghai and Xinjiang are regions where the development of the inter-subsystems is imbalanced. Areas with similar inter-system coordinated development patterns are located in Hebei, Inner Mongolia, Anhui, Henan and Tibet.

(3) The inter-subsystem coordinated development of PARs in China is significantly better than the comprehensive coordinated development of individual subsystems. The inter-subsystem comprehensive coordinated development is in a relatively good state for Shaanxi, Hainan, Shanghai, Guizhou, Fujian and Guangdong; it is in a relatively poor state for Inner Mongolia, Heilongjiang, Xinjiang, Sichuan, Yunnan and Shandong. An inter-subsystem coordinated development circle is formed by Shaanxi, Guizhou, Guangdong and Fujian, and this gradually spreads outwards (depicted by the red circle and arrow in Figure 11).

\subsection{Analyzing Comprehensive Coordination Degree of CSR3ES}

By substituting the obtained inner-system and inter-subsystem coordination degrees into Equation (7), the comprehensive coordination degrees of CSR3ES are shown in Table 6. The larger the values in the table, the higher the coordination levels, and vice versa. By using Excel and ArcGIS 10.2, a Radar chart (Figure 12) and a spatial distribution grade map (Figure 13) of the comprehensive coordination degrees is presented. As shown in Figure 13, the darker the color, the higher the coordination degree.

(1) The comprehensive coordination degrees of CSR3ES in China are not ideal, and their development is uneven in different regions (thus the many sharp corners in red dyed areas in Figure 12). The regions with a relatively comprehensively coordinated development include Shanghai, Fujian, Hainan, Shaanxi, Beijing, Zhejiang and Guangdong, and those with a comprehensively uncoordinated development include Yunnan, Hebei, Shandong, Gansu, Qinghai and Xinjiang. A positive coherent effect $(\Delta E>0)$ has been exerted on the comprehensive coordination degrees of CSR3ES by the inter-system synergistic effects of PARs (Table 6).

Table 6. Comprehensive coordination degree of CSR3ES (CCD) and coherent effects of CSR3ES for 31 PARs in China, 2013.

\begin{tabular}{ccccccccc}
\hline PARs & CCD & $\Delta E^{\mathbf{1}}$ & PARs & CCD & $\Delta E^{\mathbf{1}}$ & PARs & CCD & $\Delta E^{\mathbf{1}}$ \\
\hline Beijing & 0.6769 & $>0$ & Anhui & 0.5971 & $>0$ & Sichuan & 0.5651 & $>0$ \\
Tianjin & 0.6479 & $>0$ & Fujian & 0.6989 & $>0$ & Guizhou & 0.6113 & $>0$ \\
Hebei & 0.5527 & $>0$ & Jiangxi & 0.6179 & $>0$ & Yunnan & 0.5557 & $>0$ \\
Shanxi & 0.5935 & $>0$ & Shandong & 0.5513 & $>0$ & Tibet & 0.5779 & $>0$ \\
Inner Mongolia & 0.5954 & $>0$ & Henan & 0.5851 & $>0$ & Shaanxi & 0.6794 & $>0$ \\
Liaoning & 0.6187 & $>0$ & Hubei & 0.6442 & $>0$ & Gansu & 0.5435 & $>0$ \\
Jilin & 0.6257 & $>0$ & Hunan & 0.6194 & $>0$ & Qinghai & 0.5357 & $>0$ \\
Heilongjiang & 0.5983 & $>0$ & Guangdong & 0.6679 & $>0$ & Ningxia & 0.6372 & $>0$ \\
Shanghai & 0.7010 & $>0$ & Guangxi & 0.5715 & $>0$ & Xinjiang & 0.4658 & $>0$ \\
Jiangsu & 0.6097 & $>0$ & Hainan & 0.6887 & $>0$ & & & \\
Zhejiang & 0.6729 & $>0$ & Chongqing & 0.6331 & $>0$ & & & \\
\hline 1 $\Delta E$ indicates the positive and negative of the difference between the comprehensive coordination degree of \\
CSR3ES (CCD in Table 6) and subsystem comprehensive coordination degree (CCD in Table 2).
\end{tabular}

(2) In terms of spatial correlation, five spatial districts with different comprehensive coordination modes are formed within the 31 PARs of China. The northeastern regional group consists of Inner Mongolia, Heilongjiang, Jilin and Liaoning; the southeast regional group includes Hunan, Jiangxi, Zhejiang, Fujian and Guangdong; the central regional random mode region includes Shaanxi, Ningxia, 
Shanxi, Henan, Hubei, Chongqing, Sichuan and Gansu; the northwest regional group uncoordinated mode consists of Xinjiang, Qinghai and Gansu; and the Beijing-Tianjin-Hebei polarization mode is composed of Beijing, Tianjin, Hebei and Shandong. By definition, the group coordination or incoordination modes mean that the development of regions within a group is either coordinated or uncoordinated. Random group mode indicates that adjacent to the coordinated development regions there are both coordinated and uncoordinated developments that do not create any clustering effects. The polarization coordination mode means that the coordinated development of the central region inhibits the surrounding regions rather than enhancing them (Figure 13).

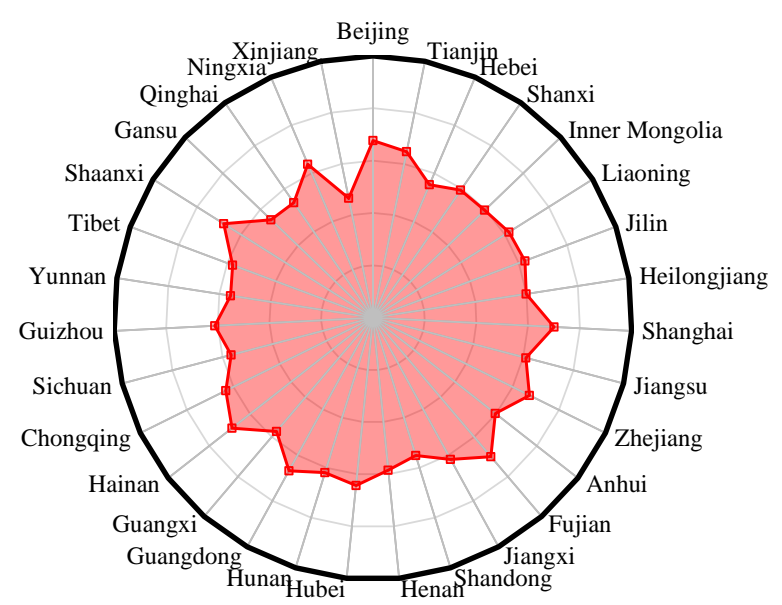

Figure 12. A radar chart of the comprehensive coordination degrees of CSR3ES for 31 PARs in China, 2013.

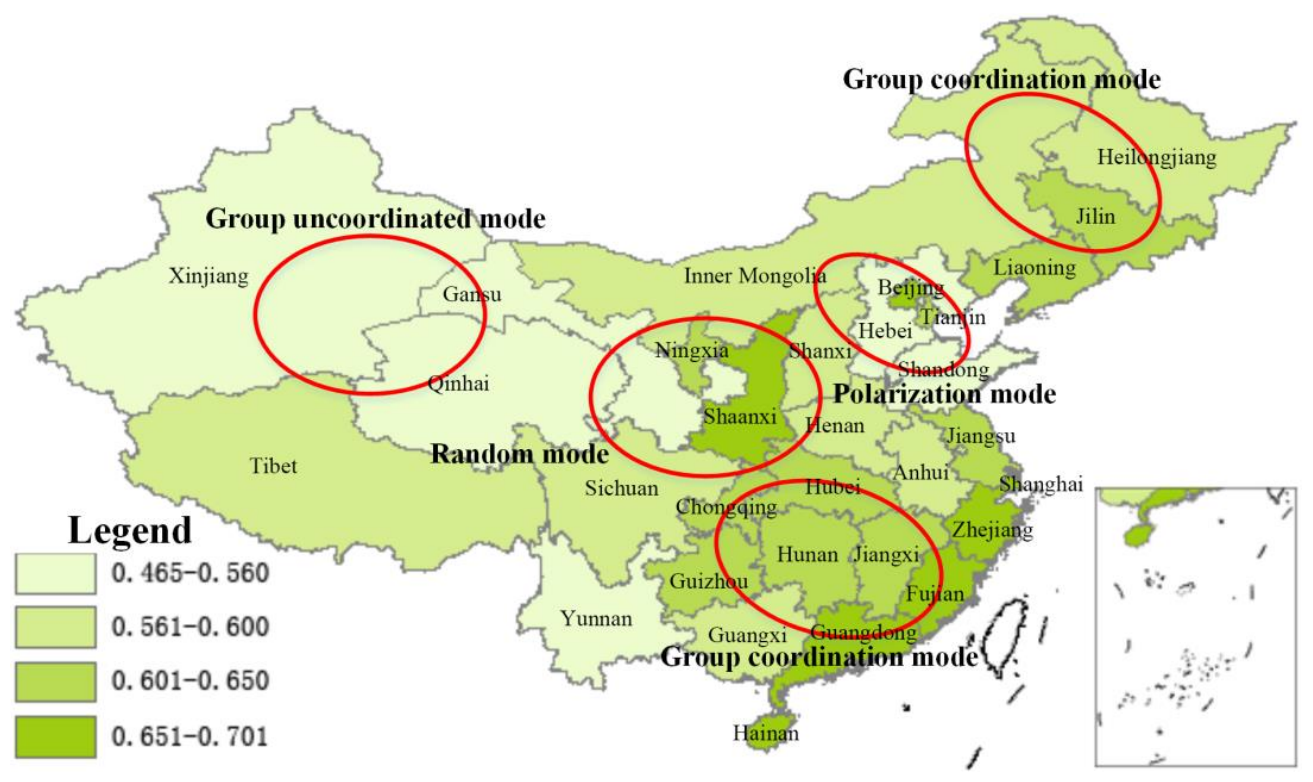

Figure 13. A spatial distribution grade map of comprehensive coordination degrees of CSR3ES for 31 PARs in China, 2013.

\subsection{Improvement and Measures for the Regional Coordinated Development of PARs}

According to the coordination management framework of CSR3ES, and based on the analytical results of the calculated inner-subsystem, inter-subsystem and comprehensive coordination of REEES subsystems of PARs, the improvement directions and corresponding measures are established, as shown in Table 7. 
Table 7. Improvement directions and corresponding measures for regional coordinated development.

\begin{tabular}{|c|c|c|c|}
\hline PARs & $\begin{array}{l}\text { Improvement } \\
\text { Directions for } \\
\text { Inner-Subsystem }\end{array}$ & $\begin{array}{l}\text { Improvement } \\
\text { Directions for } \\
\text { Inter-Subsystems }\end{array}$ & Improvement Measures \\
\hline Beijing & Ecology & Resources-Society & $\begin{array}{l}\text { Improve ecology and resources subsystems } \\
\text { to achieve coordinated development } \\
\text { between resources and society subsystems. }\end{array}$ \\
\hline Tianjin & Ecology & Ecology-Economy & $\begin{array}{l}\text { Improve ecology subsystem to achieve } \\
\text { coordinated development between ecology } \\
\text { and economy subsystems. }\end{array}$ \\
\hline Hebei & Ecology & Ecology-Society & $\begin{array}{l}\text { Improve ecology subsystem to achieve } \\
\text { coordinated development between ecology } \\
\text { and society subsystems. }\end{array}$ \\
\hline Shanxi & Resources & Resources-Society & $\begin{array}{l}\text { Improve resources subsystem to achieve } \\
\text { coordinated development between } \\
\text { resources and society subsystems. }\end{array}$ \\
\hline $\begin{array}{l}\text { Inner } \\
\text { Mongolia }\end{array}$ & Ecology & Ecology-Society & $\begin{array}{l}\text { Improve ecology subsystem to achieve } \\
\text { coordinated development between ecology } \\
\text { and society subsystems. }\end{array}$ \\
\hline Liaoning & Resources & Environment-Ecology & $\begin{array}{l}\text { Improve environment and ecology } \\
\text { subsystems to achieve their } \\
\text { coordinated development. }\end{array}$ \\
\hline Jilin & Ecology & Environment-Society & $\begin{array}{c}\text { Improve environment and society } \\
\text { subsystems to achieve coordinated } \\
\text { development between environment and } \\
\text { society subsystems. }\end{array}$ \\
\hline Heilongjiang & Resources & Resources-Ecology & $\begin{array}{l}\text { Improve resources and ecology subsystems } \\
\text { to achieve their coordinated development. }\end{array}$ \\
\hline Shanghai & Resources & Ecology-Society & $\begin{array}{l}\text { Improve resources subsystem to achieve } \\
\text { coordinated development between ecology } \\
\text { and society subsystems. }\end{array}$ \\
\hline Jiangsu & Ecology & Ecology-Economy & $\begin{array}{l}\text { Improve ecology subsystem to achieve } \\
\text { coordinated development between ecology } \\
\text { and economy subsystems. }\end{array}$ \\
\hline Zhejiang & Social & Environment-Ecology & $\begin{array}{l}\text { Improve society subsystem to achieve } \\
\text { coordinated development between } \\
\text { environment and ecology subsystems. }\end{array}$ \\
\hline Anhui & Ecology & Environment-Ecology & $\begin{array}{l}\text { Improve ecology subsystem to achieve } \\
\text { coordinated development between } \\
\text { environment and ecology subsystems. }\end{array}$ \\
\hline Fujian & Ecology & Resources-Society & $\begin{array}{l}\text { Improve ecology and society subsystems to } \\
\text { achieve coordinated development between } \\
\text { resources and society subsystems. }\end{array}$ \\
\hline Jiangxi & Social & Ecology-Economy & $\begin{array}{l}\text { Improve to society subsystem to achieve } \\
\text { their coordinated development between } \\
\text { ecology and economy subsystems. }\end{array}$ \\
\hline Shandong & Ecology & Ecology-Economy & $\begin{array}{l}\text { Improve ecology subsystem to achieve } \\
\text { coordinated development between ecology } \\
\text { and economy subsystems. }\end{array}$ \\
\hline Henan & Ecology & Ecology-Society & $\begin{array}{l}\text { Improve ecology subsystem to achieve } \\
\text { coordinated development between ecology } \\
\text { and society. subsystems }\end{array}$ \\
\hline Hubei & Ecology & Resources-Ecology & $\begin{array}{l}\text { Improve ecology and resources subsystems } \\
\text { to achieve their coordinated development. }\end{array}$ \\
\hline Hunan & Society & Ecology-Society & $\begin{array}{l}\text { Improve ecology and society subsystems to } \\
\text { achieve their coordinated development. }\end{array}$ \\
\hline
\end{tabular}


Table 7. Cont.

\begin{tabular}{|c|c|c|c|}
\hline PARs & $\begin{array}{c}\text { Improvement } \\
\text { Directions for } \\
\text { Inner-Subsystem }\end{array}$ & $\begin{array}{c}\text { Improvement } \\
\text { Directions for } \\
\text { Inter-Subsystems }\end{array}$ & Improvement Measures \\
\hline Guangdong & Ecology & Resources-Environment & $\begin{array}{l}\text { Improve ecology subsystem to achieve } \\
\text { coordinated development between } \\
\text { resources and environment subsystems. }\end{array}$ \\
\hline Guangxi & Society & Resources-Society & $\begin{array}{l}\text { Improve society subsystem to achieve } \\
\text { coordinated development between } \\
\text { resources and society subsystems. }\end{array}$ \\
\hline Hainan & Economy & Resources-Economy & $\begin{array}{l}\text { Improve economy subsystem to achieve } \\
\text { coordinated development between } \\
\text { resources and economy subsystems. }\end{array}$ \\
\hline Chongqing & Economy & Environment-ecology & $\begin{array}{l}\text { Improve economy subsystem to achieve } \\
\text { coordinated development between } \\
\text { environment and ecology subsystems. }\end{array}$ \\
\hline Sichuan & Economy & Ecology-Economy & $\begin{array}{l}\text { Improve economy and ecology subsystems } \\
\text { to achieve their coordinated development. }\end{array}$ \\
\hline Guizhou & Society & Environment-Society & $\begin{array}{l}\text { Improve society subsystem to achieve } \\
\text { coordinated development between } \\
\text { environment and society subsystems. }\end{array}$ \\
\hline Yunnan & Society & Resources-Society & $\begin{array}{l}\text { Improve society subsystem to achieve } \\
\text { coordinated development between society } \\
\text { and resources subsystems. }\end{array}$ \\
\hline Tibet & Economy & Ecology-Economy & $\begin{array}{l}\text { Improve economy subsystem to achieve } \\
\text { coordinated development between ecology } \\
\text { and economy subsystems. }\end{array}$ \\
\hline Shaanxi & Society & Resources-Economy & $\begin{array}{l}\text { Improve society subsystem to achieve } \\
\text { coordinated development between } \\
\text { resources and economy subsystems. }\end{array}$ \\
\hline Gansu & Resources & Resources-Ecology & $\begin{array}{l}\text { Improve resources subsystem to achieve } \\
\text { coordinated development between } \\
\text { resources and ecology subsystems. }\end{array}$ \\
\hline Qinghai & Resources & Resources-Ecology & $\begin{array}{l}\text { Improve resources subsystem to achieve } \\
\text { coordinated development between } \\
\text { resources and ecology subsystems. }\end{array}$ \\
\hline Ningxia & Ecology & Resources-Society & $\begin{array}{l}\text { Improve resources subsystem to achieve } \\
\text { coordinated development between } \\
\text { resources and society subsystems. }\end{array}$ \\
\hline Xinjiang & Resources & Resources-Environment & $\begin{array}{l}\text { Improve resources subsystem to achieve } \\
\text { coordinated development between } \\
\text { resources and environment subsystems. }\end{array}$ \\
\hline
\end{tabular}

\section{Discussion and Conclusions}

(1) Understanding the relationships of interdependence, mutual penetration, mutual influence and mutual restraint, as well as the differences between resources, environment, ecology, economy and society, is important from a scientific perspective. Adhering to strict scientific terminology will help to clarify the study contents of each concept body, distinguish research boundaries, and guide the establishment of the coordination analysis index system of CSR3ES as well as the design of the coordination degree measurement.

(2) When conducting the coordination analysis of CSR3ES, a set of evaluating index systems of a suitable design and high operability is urgently needed. This would enable the abstract and complicated CSR3ES to be understandable, measureable and evaluable, and therefore improve its public awareness. Additionally, this will assist decision-making departments to understand the 
developmental status and trends of the REEES subsystems, and provide data support for coordinated subsystem development and scientific decision-making. In the coordination analysis index system of CSR3ES, the indices of the elements in different hierarchies are represented and the methods are simple and easy to operate. Furthermore, the majority of information can be obtained from census and statistical data. The comprehensive indices (inner-subsystem coordination degree, inter-subsystem coordination degree and the comprehensive coordination degree of the CSR3ES) can not only evaluate the coordination degree between the various elements, but also diagnose the causes of incoordination so that appropriate improvement strategies can be incorporated. The comprehensive index system of CSR3ES satisfies the forecasting and decision-making analysis requirements, and it can be easily understood by policy makers and accepted by the public.

(3) At present, the inner-subsystem coordinated development of China is at a relatively low level. This results in a prominent incoordination of ecology and resource subsystems. By comparing the coordination of the inner-subsystem with that of the inter-subsystem, it is evident that the coordinated development of the inner-subsystem will directly impact that of the corresponding inter-subsystems. A positive effect will be exerted on the comprehensive coordination degree of CSR3ES by the inter-system synergistic effects of PARs. The regions with similar coordinated development patterns should be considered as a whole by decision-making departments when formulating relevant policies and measures to avoid wasting resources.

(4) An integrated coupling effect can be formed through the interaction and correlation of subsystems in the complex system; thus, the compressive coordination of CSR3ES solely, not a superposed coordination of individual subsystems, but rather one that considers the coherent effect on the integrated coordination by synergistic effects between the subsystems on the basis of inner-subsystem coordination. According to the integrity principle of a complex system, a measuring method for the comprehensive coordination that covers the inner-subsystem and inter-subsystem coordination was developed. Although the inter-subsystem coordination of most PARs is in an ideal state, the comprehensive coordination degrees of CSR3ES is low due to the overall low-level of subsystem comprehensive coordination degrees.

(5) The inner-subsystem comprehensive coordinated development of PARs presents a half-circle pattern, which is constituted by the coastal PARs encircling from the north, east and south. The central and western regions belong to the relatively low-level coordinated development regions. The inter-subsystem coordinated development circle is formed by Shaanxi, Guizhou, Guangdong and Fujian, and it extends to the adjacent region. In terms of spatial correlation, five comprehensive coordinated development modes of the CSR3ES are formed. These are the northeast regional coordination mode, northwest regional uncoordinated mode, southeast regional coordination mode, central regional random mode and Beijing-Tianjin-Hebei polarization mode.

(6) In this paper, the inner-subsystem coordination, inter-subsystem coordination and comprehensive coordination of the REEES subsystems in different regions were analyzed with regard to a given time or period, and they therefore cannot reveal the vertical and horizontal coordination development trends. Since the coordination itself is constantly developing, and it is subject to mutual adjustment, subsequent research to further analyze the dynamic coordination of various subsystems should focus on $T$ in the Formula $C S_{R E E E S} \subseteq\left\{S_{1}, S_{2}, S_{3}, S_{4}, S_{5}, R_{a}, T\right\}$.

Acknowledgments: This work was supported by Major consulting projects of Chinese Academy of Engineering (Project No. 2014-XZ-17) and Natural Science Foundation of China (Project No. 41401463). The Authors would like to thank the anonymous reviewers for their valuable comments, which greatly helped us to clarify and improve the contents of paper.

Author Contributions: Mingxia Xie, Jiayao Wang and Ke Chen worked collectively. Specifically, Mingxia Xie developed the original idea for the study and completed the paper. Jiayao Wang initiated the project and gave guidance in the methods. Ke Chen made contributions in data collection. All of the co-authors drafted and revised the article collectively, and all authors read and approved the final manuscript.

Conflicts of Interest: The authors declare no conflict of interest. 


\section{References}

1. Kelly, K.L. A systems approach to identifying decisive information for sustainable development. Eur. J. Oper. Res. 1998, 109, 452-464. [CrossRef]

2. Parris, T.M.; Kates, R.W. Characterizing and measuring sustainable development. Annu. Rev. Environ. Resour. 2003, 28, 1-1328. [CrossRef]

3. Lele, S.M. Sustainable development: A critical review. World Dev. 1991, 19, 607-621. [CrossRef]

4. Lin, Z.M.; Xia, B. Analysis of sustainable development ability of the urban ecosystem in Guangzhou City in the perspective of entropy. Acta Geogr. Sin. 2013, 68, 45-57. (In Chinese)

5. Jordan, S.J.; Hayes, S.E.; Yoskowitz, D.; Smith, L.M.; Summers, J.K.; Russell, M. Accounting for natural resources and environmental sustainability: Linking ecosystem services to human well-being. Environ. Sci. Technol. 2010, 44, 1530-1536. [CrossRef] [PubMed]

6. Sachs, J.D. Challenges of sustainable development under globalization. Int. J. Dev. Issues 2005, 4, 1-20. [CrossRef]

7. Young, O.R.; Lambin, E.F.; Alcock, F.; Haberl, H.; Karlsson, S.Y.; McConnell, W.J.; Myint, T.; Pahl-Wostl, C.; Polsky, C.; Ramakrishnan, P.S.; et al. A Portfolio Approach to Analyzing Complex Human-Environment Interactions: Institutions and Land Change. Ecol. Soc. 2006, 11, 3213-3217.

8. Liu, Y.Q.; Xu, J.P.; Luo, H.W. An Integrated Approach to Modelling the Economy-Society-Ecology System in Urbanization Process. Sustainability 2014, 6, 1946-1972. [CrossRef]

9. Boone, R.B.; Galvin, K.A. Simulation as an approach to social-ecological integration, with an emphasis on agent-based modeling. In Understanding Society and Natural Resources; Springer Netherlands: Dordrecht, The Netherlands, 2014; pp. 179-202.

10. Giddings, B.; Hopwood, B.; O’Brien, G. Environment, economy and society: Fitting them together into sustainable development. Sustain. Dev. 2002, 10, 187-196. [CrossRef]

11. Wang, J.H.; Tian, J.H.; Li, X.Y.; Ma, Y.J.; Yi, W.J. Evaluation of concordance between environment and economy in Qinghai Lake Watershed, Qinghai Tibet Plateau. J. Geogr. Sci. 2011, 21, 949-960. (In Chinese) [CrossRef]

12. Mao, H.Y. Study on Coordinating Development of Economic, Social Growth with Population, Resources and Environment at County Level. Acta Geogr. Sin. 1991, 46, 385-395. (In Chinese)

13. Wang, H.; Liu, F.; Yuan, Y.; Liang, W. Spatial-Temporal Analysis of the Economic and Environmental Coordination Development Degree in Liaoning Province. Geogr. J. 2013, 2013, 1-8. [CrossRef]

14. Guo, Y.T.; Wang, H.W.; Nijkamp, P.; Wu, J.G. Space-time indicators in interdependent urban-environmental systems: A study on the Huai River Basin in China. Habitat Int. 2015, 45, 135-146. [CrossRef]

15. Guan, D.J.; Gao, W.J.; Su, W.C.; Li, H.F.; Hokao, K. Modeling and dynamic assessment of urban economy-resource-environment system with a coupled system dynamics-Geographic information system model. Ecol. Ind. 2011, 11, 1333-1344. [CrossRef]

16. Tao, S.; Cai, J.M.; Chahine, T.; Xu, H.; Niu, F.Q. Modeling urban metabolism of Beijing city, China: With a coupled system dynamics: Emergy model. Stoch. Environ. Res. Risk Assess. 2014, 28, 1511-1524.

17. Wei, Y.M.; Tsai, H.T.; Fan, Y.; Zeng, R. Beijing's coordinated development of population, resources, environment, and economy. Int. J. Sustain. Dev. World Ecol. 2004, 11, 235-246. [CrossRef]

18. Yan, L.; Luo, B.R.; Ma, Y.Z.; Liu, H.L. The Structure and Application of Huge Closed-Loop System of Resources-Environment-Ecology. In Proceedings of the 2012 International Conference on Cybernetics and Informatics, Chongqing, China, 21-23 September 2012; Springer: New York, NY, USA, 2014; pp. 1047-1053.

19. Li, Y.R.; Wang, J.; Liu, Y.S.; Long, H.L. Spatial pattern and influencing factors of the coordination development of industrialization, informatization, urbanization and agricultural modernization in China: A prefecture level exploratory spatial data analysis. Acta Geogr. Sin. 2014, 69, 199-212. (In Chinese)

20. Zhang, X.; Hu, H.; Xu, J.; Yin, H.W. Coordination of urbanization and water ecological environment in Shayinghe River Basin, China. Chin. Geogr. Sci. 2011, 21, 476-495. (In Chinese) [CrossRef]

21. Li, Z.J. A Correct Understanding of Resource, Environment and Ecology. Green China 2013, 10, 46-51. (In Chinese)

22. Haken, H. Synergtics: The Mysteries of Nature; Shanghai Translation Publishing House: Shanghai, China, 2005.

23. Vattam, S.; Goel, A.K.; Rugaber, S.; Hmelo-Silver, C.E.; Jordan, R.; Gray, S.; Sinha, S. Understanding Complex Natural Systems by Articulating Structure-Behavior-Function Models. Educ. Technol. Soc. 2011, 14, 66-81. 
24. Miguel, M.S.; Johnson, J.H.; Kertesz, J.; Kaski, K.; Díaz-Guilera, A.; MacKay, R.S.; Loreto, V.; Érdi, P.; Helbing, D. Challenges in complex systems science. Eur. Phys. J. Special Top. 2012, 214, 245-271. [CrossRef]

25. Hubbard, G.D. Geographic Conditions, Influences, Controls. Ohio J. Sci. 1932, 32, 39-54.

26. Espinosa, A.; Porter, T. Sustainability, complexity and learning: Insights from complex systems approaches. Learn. Organ. 2011, 18, 54-72.

27. Šiljak, D.D. When is a complex ecosystem stable? Math. Biosci. 1975, 25, 25-50. [CrossRef]

28. Chen, C.; Huang, X.; Chen, C.L. The Coordination and Regulation of Areal System in China. Sci. Geogr. Sin. 2010, 30, 321-328. (In Chinese)

29. Ioppolo, G.; Heijungs, R.; Cucurachi, S.; Salomone, R.; Kleijn, R. Urban Metabolism: Many open questions for future answers. In Pathways to Environmental Sustainability: Methodologies and Experiences; Salomone, R., Saija, G., Eds.; Springer International Publishing AG: Dordrecht, The Netherlands, 2014; pp. $23-32$.

30. National Bureau of Statistics of China. China Statistical Yearbook; China Statistics Press: Beijing, China, 2014. (In Chinese)

31. National Bureau of Statistics of China, Ministry of Environment Protection of the People's Republic of China. China's Statistical Yearbook on Environment; China Statistics Press: Beijing, China, 2014. (In Chinese)

32. Ministry of Land and Resources of the People's Republic of China. China Land and Resources Statistical Yearbook; Geological Publishing House: Beijing, China, 2014. (In Chinese)

33. China Water Conservancy Yearbook Compilation Committee. China Water Conservancy Yearbook; Water \& Power Press: Beijing, China, 2014. (In Chinese)

34. Hwang, C.L.; Yoon, K. Methods for Multiple Attribute Decision Making; Springer Berlin Heidelberg: Berlin, Germany, 1981; pp. 58-191.

35. Xu, X.M.; Niu, D.X.; Qiu, J.P.; Wu, M.Q.; Wang, P.; Qian, W.Y.; Jin, X. Comprehensive Evaluation of Coordination Development for Regional Power Grid and Renewable Energy Power Supply Based on Improved Matter Element Extension and TOPSIS Method for Sustainability. Sustainability 2016, 8, 143-159. [CrossRef]

36. Zhang, S.H.; Wang, G.Q.; Yang, J.; Huang, L.Q.; Li, L.Q.; Qiao, F. Ecological restoration decision using compound system theory. J. Tsinghua Univ. 2011, 50, 1906-1909. (In Chinese)

(C) 2016 by the authors; licensee MDPI, Basel, Switzerland. This article is an open access article distributed under the terms and conditions of the Creative Commons Attribution (CC-BY) license (http://creativecommons.org/licenses/by/4.0/). 